\title{
SPECIFICITY OF TARGETING IN RNAi AND MIRNA PATHWAYS
}

Keywords: RNAi, siRNA, miRNA, Argonaute, off-targeting

\author{
PETR SVOBODA \\ Institute of Molecular Genetics, Academy of Sciences of the Czech Republic, \\ Videnska 1083, 14220 Prague 4, Czech Republic \\ Correspondence to: Petr Svoboda, Institute of Molecular Genetics ASCR, \\ Videnska 1083, 14220 Prague 4, Czech Republic, tel. \# +420 241063147, \\ e-mail: svobodap@img.cas.cz.
}

\begin{abstract}
This review systematically covers sequence-specific gene regulation by miRNAs and dsRNA-derived siRNAs in animals and plants from the perspective of target RNA recognition, potential for non-target (off-target) effects, and reliable determination of biological effects of small RNAs in animals and plants. I will review sequence complementarity between target RNA and small RNA (siRNA or miRNA), including tolerance to mismatches, parameters influencing sequence complementarity (and target recognition and repression) and discuss specificity of targeting by miRNAs and off-targeting by siRNAs. In addition, I will discuss reliable identification of target RNAs (and, eventually, biological effects). Accordingly, the text is divided into the following four sections: (I) Small RNA:target RNA base pairing, (II) Other key factors influencing target recognition and repression, (III) Off-targeting - causes and remedies, (III) Smal RNA target identification.
\end{abstract}

\section{Introduction}

Within the complex world of RNA silencing, two related yet distinct pathways exist in animals and plants: RNA interference (RNAi) and microRNA (miRNA) pathways (Fig. 1). Both pathways employ small RNAs loaded on Argonaute proteins as sequence-specific guides for post-transcriptional repression. The elementary difference between these two pathways is that miRNA pathways employ genome-encoded small RNAs with defined sequences (i.e. miRNAs can be annotated) while RNAi is initiated by processing long double-stranded RNA (dsRNA) into a mixture of short interfering RNAs (siRNAs). Thus, the miRNA pathway in a cell employs a population of miRNA molecules that can be clustered based on unique sequences, corresponding to specific positions in miRNA precursors. In other words, the major distinction between RNAi and miRNA pathways is the origin of small RNAs and their information content. In terms of their mode of action, siRNAs and miRNAs can be in some cases indistinguishable. 


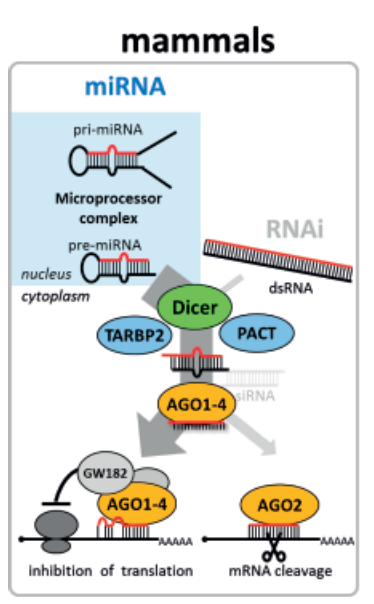

\section{Drosophila (Arthropoda)}

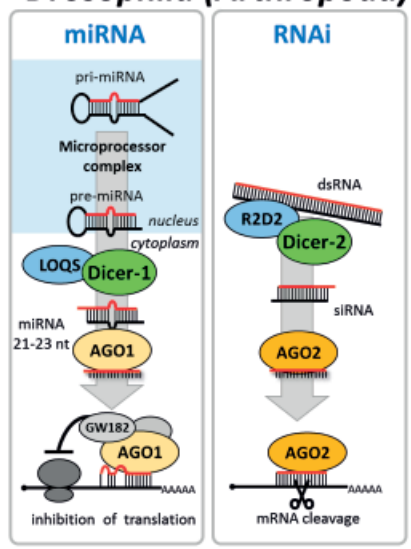

\section{Caenorhabditis (Nematoda)}
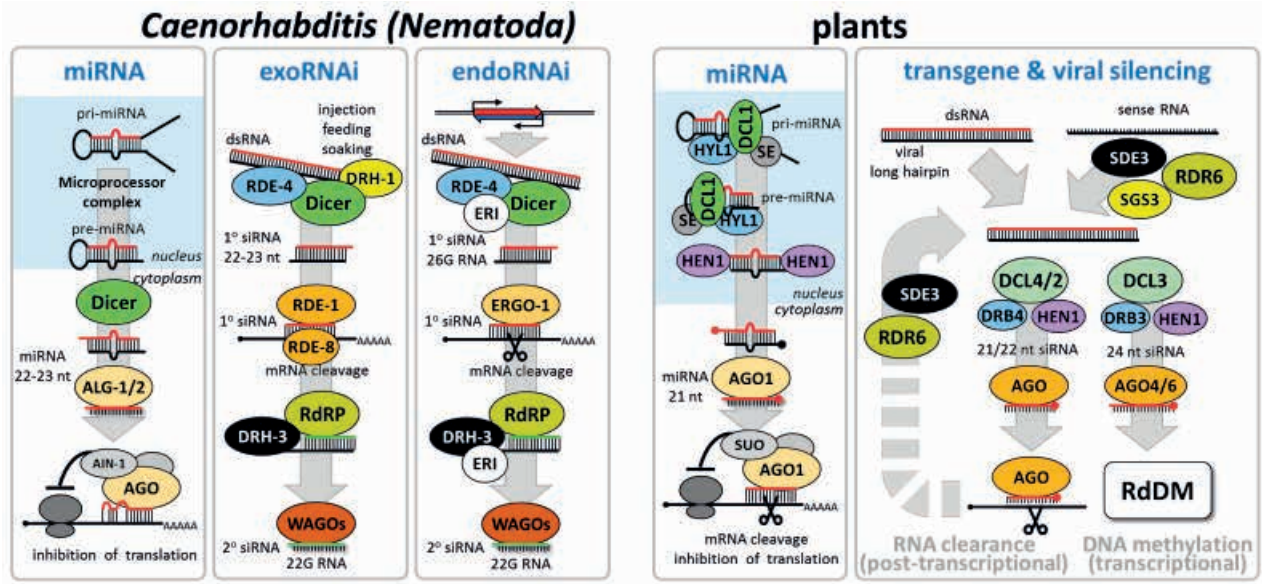

Figure 1 miRNA and RNAi pathways in animals and plants

The schemes depict key components of miRNA and RNAi pathways in the main eukaryotic model systems

In animals, the miRNA pathway, which is primarily a gene-regulating pathway, is highly conserved. The canonical miRNA biogenesis is a spatially separated into two-steps. The first step takes place in the nucleus where RNase III Drosha, a component of the Microprocessor complex, releases a precursor miRNA (pre-miRNA) from a primary miRNA transcript (pri-miRNA). Next, a pre-miRNA is transported to the cytoplasm where it is cleaved by a second RNase III Dicer. Dicer releases a miRNA duplex of which one strand will be loaded on an Argonaute protein. The miRNA pathway in plants operates similarly but employs only a single nuclear Dicer-like 1 (DCL1) RNase III to produce pre-miRNAs and miRNAs. The second important difference is the methylation of plant miRNAs at their 3' end mediated by HEN1 methyltransferase. 
The RNAi pathway is much more diverse across animals and plants. It is conceivable given the antiviral role of RNAi where the parasite:host interactions can accelerate evolution of RNAi pathways in different taxons. Despite the differences, RNAi and miRNA pathways share common features, which include biogenesis of small RNAs involving Dicer and effector complexes containing an Argonaute protein carrying a small RNA. Argonaute proteins are composed of four main domains: the central PAZ domain, the C-terminal PIWI (P-element induced wimpy testis), the N-terminal domain, and the MID domain between PAZ and PIWI domains (Fig. 2). The PIWI domain has an RNase H-like fold and carries a "slicer" activity (Ma et al., 2005; Parker et al., 2004; Song et al., 2004; Yuan et al., 2005). Argonaute proteins fall into three distinct groups (reviewed in Faehnle and Joshua-Tor, 2007): (1) AGO proteins, found in all kingdoms, (2) PIWI proteins found in animals, and (3) WAGO proteins found only in nematodes.

From the mechanistic perspective, post-transcriptional repression by small RNAs employs two distinct yet related (and often overlapping) modes of action:

Direct endonucleolytic RNA cleavage mediated by the so-called "slicer" activity of an Argonaute protein. This mode of action needs two conditions to be met: (i) the Argonaute protein has the slicer activity (not all family members have it) and (ii) there needs to be extensive base pairing between the Argonaute-bound small RNA and the cognate RNA. Extensive base pairing positions the cognate RNA such that it can be sliced in the position corresponding the middle of the guiding small RNA. This mode of action has been traditionally associated with RNAi and will be refered to as "RNAi-like" targeting. However, it should be pointed out that the two conditions for RNA-like targeting do not exclude miRNAs and, in fact, it is well established that miRNAs loaded on a slicing Argonaute would guide slicing of perfectly complementary cognate RNAs.

Indirect mRNA destabilization, which is found when an Argonaute protein lacks the slicing activity or the base pairing is incomplete and prevents positioning of the cognate RNA (typically lack of base pairing in the middle of the small RNA:target RNA duplex. In these cases, Argonaute-bound small RNAs provide sufficiently stable interaction for target recognition while the repression is mediated by Argonaute-interacting partners. While the precise mode of action is still debated and may vary between different cell types and model systems, it seems to be coupled with common mechanisms of mRNA destabilization, i.e. deadenylation and decapping.

At least four types of RNAi \& miRNA pathway combinations can be recognized in animals and plants (Fig. 1):

(I) overlapping miRNA and RNAi pathways with a single-set of Dicer and Argonaute proteins and without an RNA-dependent RNA polymerase (RdRP) - typical for vertebrates especially mammals. The molecular machinery in the cell primarily produces miRNAs but it can also support canonical RNAi, which can be observed under rare circumstances. The term RNAi in mammals is commonly used for RNAi-like cleavage mediated by a siRNA loaded on AGO2. However, siRNAs are being loaded on all four mammalian AGO protein (Meister et al., 2004), and once loaded, their behavior is indistinguishable from miRNAs. This functional overlap at the level of the effector complex is the major source of the so-called "off-targeting" phenomenon where siRNAs target also other mRNAs through miRNA-like mode of action. 
(II) separated miRNA and RNAi pathways with dedicated Dicer and Argonaute proteins (no RdRPs). This arrangement is observed in Arthropods (Drosophila).

(III) distinct miRNA pathway and a complex RNAi system employing RdRp(s) sharing a single Dicer. This arrangement is observed in nematodes where expansion of Argonaute proteins created a highly complex RNA silencing system

(IV) separated miRNA pathway and a complex RNAi system employing RdRp(s) with multiple Dicer and Argonaute proteins. This arrangement is observed in plants.

Mechanistical aspects of target recognition and its specificity will be discussed next.

\section{Small RNA:target RNA base pairing}

A small RNA loaded on an Argonaute protein functions as a guide selectively recognizing cognate RNAs through sequence complementarity. Sequence complementarity can be high (full or almost full) or partial. High sequence complementarity operates in RNAi-mediated innate immunity and genome defense where it is desirable to degrade all nucleic acids with highly similar sequences. High sequence complementarity is also observed for many plant miRNAs, which could be, at least in part, a consequence of their evolution (Allen et al., 2004; Llave et al., 2002). Animal miRNAs and some plant miRNAs have typically partial sequence complementarity, which seems to be non-randomly distributed along a small RNA (reviewed, for example in Bartel, 2009). Partial complementarity could be seen as a minimal requirement for functional target recognition formed by natural selection. However,

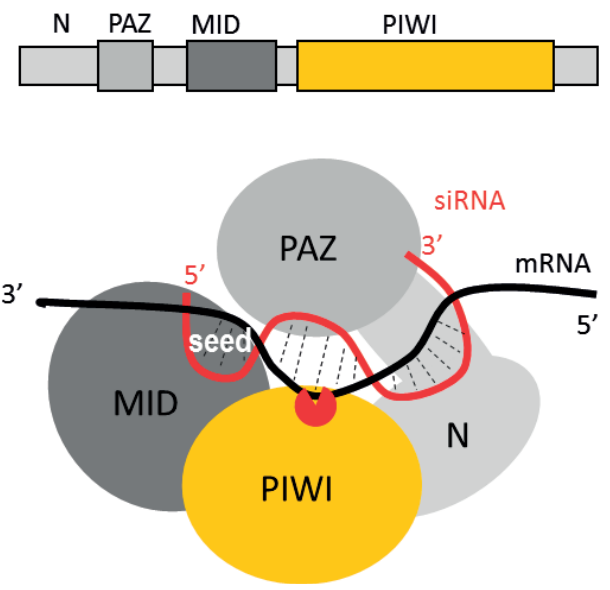

Figure 2 Argonaute protein structure

Schematic domain organization of an Argonaute protein. The scheme shows how a siRNA-loaded Argonaute cleaves a perfectly complementary RNA, which becomes accessible by the catalytical center in the PIWI domain upon base pairing with a small RNA. Nucleotides 2-8 of the small RNA initiate the interaction with the cognate RNA and form the so-called "seed", which has a highly predictive value for miRNA binding sites and siRNA off-targeting. The cognate mRNA is cleaved in the middle of the base paired sequence by the slicer activity depicted as a red pac-man. 
before addressing small RNA:target RNA complementarity, I will review the structure of Argonaute proteins and its implications for base pairing and target recognition. The reason is that structural analyses of Argonaute proteins provided important insights into the mechanism of how an Argonaute-loaded small RNA recognizes and binds its target.

\section{Structural insights into target recognition by Argonaute-bound small RNAs}

The one of the fundamental steps in deciphering rules governing target recognition and repression in RNA silencing is understanding the structure of a cognate RNA bound to a guide RNA loaded on an Argonaute protein. The pioneering structural analysis of fulllength Argonaute proteins has been carried out on crystalized archaeal proteins from Pyrococcus furiosus (Song et al., 2004), Aquifex aeolicus (Yuan et al., 2005), Archaeglobus fulgidus (Ma et al., 2005; Parker et al., 2005), and Thermus thermophiles (Wang et al., 2008; Wang et al., 2009) and, subsequently on human AGO1 and AGO2 proteins (Elkayam et al., 2012; Faehnle et al., 2013; Nakanishi et al., 2013; Schirle et al., 2016; Schirle and MacRae, 2012; Schirle et al., 2015; Schirle et al., 2014).

Structural analysis of archaeal proteins revealed that Argonaute proteins are composed of four main domains: the central PAZ domain, the C-terminal PIWI, the N-terminal domain, and the MID domain between PAZ and PIWI domains. A small RNA is anchored with its 3 ' end in the PAZ domain and the 5' end in a binding pocket between the MID domain and the PIWI domain (Fig. 2). Human AGO1 and AGO2 proteins also show this organization (Elkayam et al., 2012; Faehnle et al., 2013; Nakanishi et al., 2013; Schirle et al., 2016; Schirle and MacRae, 2012; Schirle et al., 2015; Schirle et al., 2014). While both proteins accommodate siRNAs and miRNAs, only AGO2 has the slicer activity (Liu et al., 2004; Meister et al., 2004). The crystal structure of human AGO2 revealed a bilobed molecule with a central cleft for binding guide and target RNAs (Elkayam et al., 2012; Schirle and MacRae, 2012; Schirle et al., 2015; Schirle et al., 2014). The crystal structures of human AGO1 bound to endogenous co-purified RNAs or loaded with miRNA (let-7) are very similar to the structures of AGO2 despite the fact that AGO1 lacks the slicer activity (Faehnle et al., 2013; Nakanishi et al., 2013).

The key observation coming from the structural analysis is that nucleotides 2 to 6 of a guide RNA are positioned in an A-form conformation for base pairing with target messenger RNAs (Elkayam et al., 2012; Faehnle et al., 2013; Nakanishi et al., 2013; Schirle et al., 2016; Schirle and MacRae, 2012; Schirle et al., 2015; Schirle et al., 2014) (Fig. 3). An RNA molecule can occur in many three dimensional conformations because there are multiple angles along which it can rotate its parts. Accordingly, initiation of base pairing requires proper conformation of two RNA molecules in order to initiate formation of hydrogen bonds between two complementary molecules. An Argonaute protein facilitates base pairing between a small RNA and a complementary RNA (= target recognition) by exposing nucleotides 2-6 arranged in a conformation needed for proper base pairing.

Between nucleotides 6 and 7, there is a kink that may function in miRNA target recognition or release of sliced RNA products. (Schirle and MacRae, 2012). Crystallization of loaded human AGO2 in the presence of target RNA sequences suggested a stepwise mechanism for interaction with cognate RNAs. First, AGO2 exposes guide nucleotides (nt) 2 to 
A

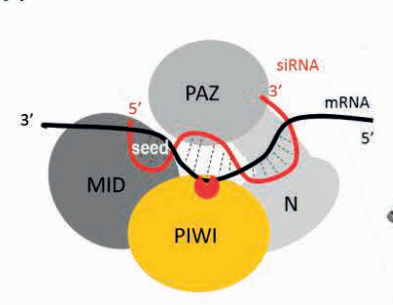

B

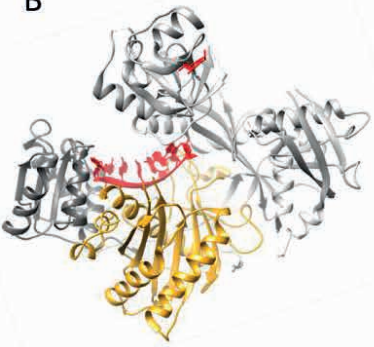

C

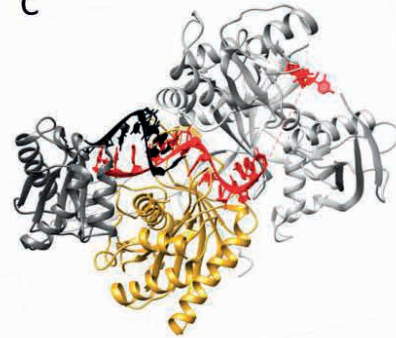

Figure 3 Crystal structures of Argonautes with bound RNAs

(A) A schematic depiction of AGO2 domain organization. (B) AGO2 with bound small RNA (in red), visible is the seed in A conformation (Schirle et al., 2014). (C) AGO2 loaded with a small RNA (in red) interacting with a target RNA (in black) (Schirle et al., 2014). Data for visualization were obtained from wwPDB and displayed in UCSF Chimera.

5 for initial target pairing, which then promotes conformational changes that expose nt 2 to 8 and 13 to 16 for further target recognition (Schirle et al., 2014). miRNA binding seem to lock the otherwise flexible AGO2 enzyme in a stable conformation (Elkayam et al., 2012). The structure of human Ago2 bound to miR-20a implies that the miRNA is anchored at both ends by the MID and PAZ domains with several kinks and turns along the binding groove (Elkayam et al., 2012). Spurious slicing of miRNA targets is avoided through an inhibitory coordination of one catalytic magnesium ion (Schirle et al., 2014). Evolutionary changes that rendered hAGO1 inactive included a mutation of a catalytic tetrad residue and mutations on a loop near the actives site (Faehnle et al., 2013; Nakanishi et al., 2013). Importantly, the PIWI domain contains tandem tryptophan-binding pockets, that function in recruitment of glycine-tryptophan-182 (GW182) or other tryptophan-rich cofactors (Schirle and MacRae, 2012). Computer simulation of the structural and functional dynamics of human $\mathrm{AGO} 2$ and the interaction mechanism with siRNAs confirmed that AGO2 adopts two conformations such as "open" and "close" and the PAZ is a highly flexible region. (Bhandare and Ramaswamy, 2016). Models of miRNA-loaded Argonautes imply that Argonautes adopt variable conformations at distinct target sites that generate distorted, imperfect miRNA-target duplexes where structural distortions are better tolerated in solvent-exposed seed and 3'-end regions than in the central duplex region (Gan and Gunsalus, 2015).

Structural analysis also clarified the effect of the first nucleotide in the cognate site, which does not base pair with the loaded small RNA because the first nucleotide of the small RNA (frequently U) is buried in the 5' end-binding pocket. Yet, it was observed that interaction with the cognate site is enhanced by adenosine in the position 1 of a miRNA binding site; the structural analysis revealed that the adenosine in the mRNA is recognized indirectly by $\mathrm{AGO} 2$ through a hydrogen-bonding network of water molecules that preferentially interacts with the N6 amine on the adenine base (Schirle et al., 2015). Importantly, N6 adenosine methylation blocks recognition of the adenosine, which might reflect a possible mechanism for regulating of miRNA binding through covalent modification of miRNA binding sites (Schirle et al., 2015). 


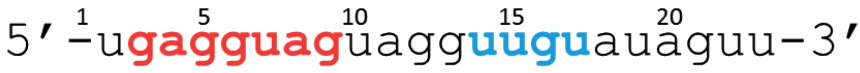 \\ seed $(2-8)$ \\ central $\prod_{\text {3' supplementary }}$}

Figure 4 Small RNA domains.

Small RNAs loaded onto AGO proteins can be divided into modules including the 5 ' the anchor, seed sequence, central part, 3' supplementary sequence, and tail (Wee et al., 2012).

These data provide structural foundations of many features of target recognition and can be used for computer simulations of miRNA-target interaction in the context of the loaded Argonaute structure. In fact, an algorithm MiREN, which builds and scores three-dimensional models of the ternary complex formed by AGO, a miRNA and $22 \mathrm{nt}$ of a target mRNA, can be used to assess the likelihood that an RNA molecule is the target of a given miRNA (Leoni and Tramontano, 2016).

Importantly, they also explain features associated with different regions of miRNA and siRNA sequences that were identified in kinetic and bioinformatics studies. Taken together, crystal structures of AGO2 explain the nucleotide-pairing patterns that emerged during previous studies of miRNA sequences, namely analyses of conservations of miRNA binding sites and biochemical analyses of target recognition, which are discussed later.

\section{small RNA:target RNA base pairing}

Sequence complementarity between a small RNA and its target RNA can be full (or almost full) or partial. Full complementarity is typically associated with siRNAs while partial with miRNAs although imperfect base pairing of siRNAs and perfect base pairing of miRNAs also occur. To provide a framework for this section, I first review the full-complementarity, then the partial complementarity involving base pairing of 5' small RNA nucleotides (the seed, Fig. 4) and then seedless (non-canonical, non-seed) interactions and their implications on target recognition, prediction and effective repression. Importantly, target mRNAs are as efficiently repressed by microRNA-binding sites in the 5 'UTR as in the 3 'UTR as shown in experiments in cultured human cells (Lytle et al., 2007).

\section{siRNA complementarity and sequence features}

RNAi efficiency correlates well with the binding energy of a siRNA to its mRNA target (Muckstein et al., 2006). While full complementarity yields a perfect duplex in which all nucleotides participate seemingly equally, some positive correlations were identified between positions of specific nucleotides and siRNA suppressing efficiency. These features may reflect positive effects on Argonaute loading (strand selection) as well as on target recognition. Analysis of the efficiency of $\sim 600$ siRNAs suggested higher siRNA efficiency with $\mathrm{A} / \mathrm{U}$ at positions 10 and 19 , a G/C at position 1, and more than three A/Us between positions 13 and 19, in the sense strand of the siRNA sequence (Jagla et al., 2005). Furthermore, specific residues at every third position of an siRNA influence its efficient RNAi 
activity, which might reflect interaction with TARBP2 during formation of the RNA-induced silencing complex (RISC) (Katoh and Suzuki, 2007).

Target recognition by siRNAs is highly specific. However, discrimination of RNAi between two sequences differing by a single nucleotide varies according to the position of the mismatch. A systematic analysis of single-nucleotide mutations in target sites of a functionally validated siRNA showed that the position of the mismatched base pair and the identity of the nucleotides forming the mismatch matter for effective silencing (Du et al., 2005). A:C mismatches were, in addition to the G:U wobble base pairs, surprisingly well tolerated and target sites containing such mismatches were silenced almost as efficiently as with full complementarity (Du et al., 2005). G:U wobble base pairing in the central part of the antisense strand caused a pronounced decrease in activity, while mutations at the 5, and 3'ends were well-tolerated (Holen et al., 2005). Interestingly, analysis of siRNA selectivity suggested that siRNAs with G:U wobble base pairs or a mismatches located in the "seed" are discriminating less between perfect and mismatched target than those in which the mismatch was located 3' to the seed (nucleotides 9-14); this region is critical for target cleavage but not siRNA binding (Schwarz et al., 2006).

\section{miRNAs with extensive base pairing}

Target recognition by miRNAs in plants is commonly thought to involve extensive base pairing and RNAi-like cleavage of the target (reviewed in Axtell, 2013; Wang et al., 2015). This notion stems from the perfect complementarity between miR171 and its SCARECROW-LIKE (SCL) mRNA target, which was the first identified miRNA:mRNA interaction in plants (Llave et al., 2002). However, the perfect complementarity is rather an exception as most of the identified miRNA targets in plant cells have some imperfect base pairing (summarized in (Jones-Rhoades and Bartel, 2004; Jones-Rhoades et al., 2006)). Extensive base pairing and microRNA-directed RNAi-like cleavage exists also in animals but it is rare; one of the exceptional cases is HOXB8 mRNA cleavage by miR-196 (Yekta et al., 2004)

Mismatches to the miRNA 5' regions strongly reduce repression but are found in several natural miRNA-binding sites while miRNA binding with a few mismatches to the miRNA 3 ' regions are common in plants and are often equally (or even more) effective as perfectly matched sites (Liu et al., 2014b). Central mismatches interfere with repression (Liu et al., 2014b). However, miR398 in Arabidopsis binds 5'UTR of the blue copper-binding protein mRNA with a bulge of six nucleotides opposite to the 5' region of the miRNA (Brousse et al., 2014). These and other studies led to consensus base pairing rules for a functional plant miRNA-target interaction: little tolerance for mismatches at positions $2-13$, with especially little tolerance of mismatches at positions 9-11, and more tolerance of mismatches at positions 1, and 14-21 (Wang et al., 2015). This is in contrast with animal miRNAs where pairing at positions 2-7 can be sufficient for a functional interaction (Bartel, 2009).

High sequence complementarity in mammals may be coupled with Argonaute "unloading". It was found that highly complementary target RNAs significantly accelerate release of the guide RNA from Ago2. Unloading can be enhanced by mismatches between the 
target and miRNA's 5' end and attenuated by mismatches to miRNA's 3' end (De et al., 2013).

\section{Imperfect base pairing of miRNAs}

Animal miRNAs typically base pair imperfectly with their targets. Target sites can be grouped into two broad categories. 5' dominant sites have sufficient complementarity to the miRNA 5' end to function with little or no support from pairing to the miRNA 3' end. Indeed, sites with $3^{\prime}$ pairing below the random noise level are functional given a strong 5 ' end. In contrast, 3' compensatory sites have insufficient 5' pairing and require strong 3 ' pairing for function (Brennecke et al., 2005). Accordingly, I will separately discuss the canonical base pairing involving miRNA's 5' end (the seed) and the non-canonical (seedless) interactions. I will start with the canonical interaction involving base pairing of the seed because it is the most studied and integrates knowledge from structural studies as well as sequence analyses.

\section{Seed-involving interactions}

The seed sequence concept emerged already during pioneering work on miRNA annotation where it became apparent that miRNAs form families sharing 5' sequences (Lagos-Quintana et al., 2001; Lau et al., 2001; Lee and Ambros, 2001). Then it became clear that the seed sequence is a strong predictor for miRNA targets (Lewis et al., 2005; Sood et al., 2006) as well as for siRNA off-targeting (Jackson et al., 2006b). An analysis of more than 18,000 high-confidence miRNA-mRNA interactions suggested that binding of most miRNAs includes the 5' seed region, while around $60 \%$ of seed interactions contained bulged or mismatched nucleotides (Helwak et al., 2013). The molecular mechanism of miRNA and target recognition (reviewed in Bartel, 2009) provides an explanation for the significance of the seed sequence and, while there are also small RNA:target mRNA interactions that do not involve the seed sequence, the concept of the seed is sufficient to explain that any AGO-loaded small RNA in any cell type has the potential to interact with hundreds and thousands of different mRNAs. In fact the estimates for human mRNAs targeted by miRNAs are between 30 and $>60 \%$ (Friedman et al., 2009; Lewis et al., 2005).

The seed region is generally defined as a 7 nt region mapping to positions $2-8$ and it strongly confers specificities of animal miRNAs to their mRNA targets. There is a high functional cost of even single nucleotide changes within seed regions, which is consistent with their high sequence conservation among miRNA families both within and between species and suggests processes that may underlie the evolution of miRNA regulatory control (Hill et al., 2014). The target specificity determined by the seed has evolutionary and biological implications because single nucleotide polymorphisms in canonical miRNA binding sites would affect miRNA-mediated regulations, a notion supported also by experimental data (Afonso-Grunz and Muller, 2015; Vosa et al., 2015).

The canonical 7nt seed can be divided into several types (Ellwanger et al., 2011). More specifically, the core seeds have been described as a 6-mer (bases 2-7), 7-mer ("7-mer-A1" being bases $1-7$, and " 7 -mer-m 8 " being bases $2-8$ ), and 8 -mer (bases 1-8); sometimes the 
7-mer-A1 and 8-mer seeds are required to have an adenine, 'A', as the first nucleotide types (Bartel, 2009; Ellwanger et al., 2011).

Longer seeds, i.e. seeds of 7 or 8 nucleotides in length are more evolutionarily conserved than shorter ones (Ellwanger et al., 2011). Longer seeds confer higher specificity and repression. It was reported that the extent of the seed match has a strong impact on resulting target repression: single 8 mer seed match mediates down-regulation comparable to two 7 mer seed matches (Nielsen et al., 2007). However, others did not observe a linear relationship between seed length and miRNA expression dysregulation, which does not support the hypothesis the seed region length alone influences mRNA repression. (Mullany et al., 2016)

In any case, the majority of functional target sites seems formed by less specific seeds of only $6 \mathrm{nt}$ indicating a crucial biological role of this type (Ellwanger et al., 2011). In fact, pairing at positions $2-7$ is sufficient for a functional interaction of animal miRNAs with their targets (Bartel, 2009). In contrast, seed pairing does not appear to be critical for land plant miRNAs (Liu et al., 2014b).

The minimal requirement for miRNA:mRNA interactions in animals explains the large numbers of targets of animal miRNAs and the fact that, the majority of functional sites is poorly detected by common prediction methods (Ellwanger et al., 2011). While the initial studies suggested that average miRNAs have approximately 100 target sites (Brennecke et al., 2005), subsequent bioinformatics and experimental identification of miRNA targets suggest even higher number of target sites.

There are several targeting determinants that enhance seed match-associated mRNA repression, including the presence of adenosine opposite miRNA base 1 (this functionality is explained by Argonaute protein structure (Schirle et al., 2015)) and of adenosine or uridine opposite miRNA base 9 , independent of complementarity to the siRNA/miRNA (Lewis et al., 2005; Nielsen et al., 2007). Furthermore, seed-based canonical target recognition was dependent on the GC content of the miRNA seed - low GC content in the seed was coupled with non-canonical target recognition. (Wang, 2014). Additional reported determinants beyond seed pairing include: AU-rich nucleotide composition near the site, proximity to sites for co-expressed miRNAs (which leads to cooperative action), proximity to residues pairing to miRNA nucleotides 13-16, positioning within the $3^{\prime} \mathrm{UTR}$ at least $15 \mathrm{nt}$ from the stop codon, and positioning away from the center of long UTRs (Grimson et al., 2007).

\section{Non-canonical - non-seed interactions}

There is large variety of miRNA-target duplex structures, which include seedless interactions (reviewed in Cipolla, 2014; Seok et al., 2016a). The existence of seedless interactions explains reports that perfect seed pairing is not a generally reliable predictor for miRNA-target interactions (Didiano and Hobert, 2006). Despite attempts to classify non-canonical interactions (Xu et al., 2014b) and tertiary structure-based modelling of miRNA interactions (Gan and Gunsalus, 2015), bioinformatic prediction of non-canonical interactions is far from ideal. A solution is integration of bioinformatic target prediction with biochemically identified miRNA binding sites. Such analyses suggested that most miRNA targets were of a non-canonical type, i.e. not involving perfect complementarity in the seed region 
(Khorshid et al., 2013; Wang, 2014). Importantly, analysis of AGO-associated mRNAs that lack seed complementarity with miRNAs suggested that AGO might have its own binding preference within target mRNAs, independent of guide miRNAs (Li et al., 2014). A structurally accessible and evolutionarily conserved region ( $\sim 10$ nucleotides in length) was identified that alone can accurately predict AGO-mRNA associations, independent of the presence of miRNA binding sites (Li et al., 2014). In any case, the impact of non-canonical targeting regarding target downregulation is not fully resolved (Khorshid et al., 2013; Martin et al., 2014; Wang, 2014).

\section{Other important factors influencing target recognition and repression}

It is important to recognize that sequence complementarity between a small RNA and its putative target is not sufficient to make any prediction about silencing of the target because there are other important factors at play. The two most important are discussed in the next two sections are (I) the binding site accessibility and (II) stoichiometry between a small RNA ant its target (or binding kinetics). Other factors, which might contribute to silencing in a context-dependent manner are, for example, alternative polyadenylation and arrangement of miRNA binding sites in 3'UTRs might cause different effects in different cells (Hon and Zhang, 2007; Majoros and Ohler, 2007; Nam et al., 2014a). In particular, there was a strong preference reported for targets to be located in close vicinity of the stop codon and the polyadenylation sites. (Majoros and Ohler, 2007).

\section{Binding site accessibility}

Mere sequence complementarity is not a sufficient predictor whether base pairing will occur in vivo. RNA molecules always form secondary structures and, in the cellular context, a number of proteins interacts with RNA molecules. Accordingly, secondary structures or RNA binding proteins may prevent base pairing of two complementary sequences. The issue of sequence accessibility was recognized during early RNAi experiments with stochastic knockdown efficiency. When searching for factors influencing knock-down efficiency, attention turned to the local RNA structure at siRNA target sites and it was demonstrated that local RNA target structure is an important factor for siRNA efficacy (Schubert et al., 2005). Accordingly, siRNA design tools started to accommodate not only properties of siRNAs but also properties of the target site because it strongly increased efficiency of designed siRNAs (Heale et al., 2005, 2006; Shao et al., 2007; Tafer et al., 2008).

Systematic investigation of siRNA:target RNA interactions and the effect of local secondary structures provided also insights into the molecular mechanism of target recognition. It was shown in vitro and in vivo, that the accessibility of the target site correlates directly with the efficiency of cleavage, demonstrating that RISC is not unfolding structured RNA (Ameres et al., 2007). During target recognition, RISC transiently contacts single-stranded RNA nonspecifically and promotes siRNA-target RNA annealing (Ameres et al., 2007).The seed of Argonaute-associated siRNA creates a thermodynamic threshold that determines the stable association of RISC and the target RNA (Ameres et al., 2007). 
The same principles apparently apply for miRNA-mediated repression (Long et al., 2007; Xu et al., 2014b). Mutations diminishing target accessibility substantially reduce microRNA-mediated translational repression, with effects comparable to those of mutations that disrupt sequence complementarity (Kertesz et al., 2007).

\section{small RNA:target RNA stoichiometry and binding kinetics}

The second critical factor for target repression is stoichiometry between a small RNA ant its target. This is especially important for the miRNA-like type of target repression because a miRNA must remain associated with its target RNA in order to induce its translational repression and degradation. Thus, suppression of a specific mRNA by a miRNA requires enough miRNA molecules that would assure enough interactions with binding sites in that particular RNA while these binding sites essentially compete with all binding sites for that miRNA in the transcriptome.

\section{Biochemical analyses of stoichiometry and kinetics}

Kinetic data should be taken as a biochemical range for any hypotheses concerning target recognition and biological effects of small RNAs in the context of loaded RISC. Among these is a detailed kinetic study of Drosophila and mouse AGO2 RISCs (Wee et al., 2012).

It was shown that siRNA-programmed RISC is a classical Michaelis-Menten enzyme in the presence of ATP (Haley and Zamore, 2004). In the absence of ATP, the rate of multiple rounds of catalysis is limited by release of the cleaved products (Haley and Zamore, 2004). Kinetic analysis suggests that different regions of the siRNA play distinct roles in the cycle of target recognition, cleavage, and product release (Haley and Zamore, 2004). Later, it was shown that Argonaute divides its RNA guide into domains with distinct functions and RNA-binding properties. (Wee et al., 2012) According to this analysis, small RNAs loaded onto AGO proteins are actually composed of five distinct modules the anchor, seed, central, 3' supplementary, and tail (Fig. 4) (Wee et al., 2012). Bases near the siRNA 5' end disproportionately contribute to target RNA-binding energy, whereas base pairs formed by the central and 3' regions of the siRNA provide a helical geometry required for catalysis (Haley and Zamore, 2004). Mouse AGO2, which mainly mediates miRNA-directed repression in vivo, dissociates rapidly and with similar rates for fully paired and seed-matched targets (Wee et al., 2012). An important conclusion from this study is that low-abundant miRNAs are unlikely to contribute much biologically meaningful regulation because they are present at a concentration less than their KD for seed-matching targets, which are in a picomolar range (Wee et al., 2012). Another study characterized siRNA binding, target RNA recognition, sequence-specific cleavage and product release by recombinant human Ago 2 (hAgo2). This yielded a minimal mechanistic model describing fundamental steps during RNAi, which is consistent with a "two-state" model of RISC action (Deerberg et al., 2013). Finally, it was found that $\mathrm{Mg} 2+$ concentration, influences AGO2 structural flexibility and is important for its catalytic/functional activity, with low $[\mathrm{Mg} 2+]$ favoring greater Ago2 flexibility (e.g., greater entropy) and less miRNA/mRNA duplex stability, thus favoring slicing(Nam et al., 2014b). 
Importantly, it seems that miRNA:mRNA stoichiometry cannot be simply determined by quantifying RNAs. Quantification of Argonaute-associated endogenous miRNAs or exogenous siRNAs in cultured cells suggested that only a small proportion (even $<10 \%$ ) of such small RNAs is loaded on Argonautes (Janas et al., 2012; Stalder et al., 2013). Furthermore, a substantial percentage of the miRNA pool associated with mRNAs without Argonautes (Janas et al., 2012; Stalder et al., 2013). It was also found that endogenous human miRNAs vary widely, by $>100$-fold, in their level of RISC association and show that the level of Ago binding is a better indicator of inhibitory potential than is the total level of miRNA expression (Flores et al., 2014). Together, these data indicate that the level of RISC association of a given endogenous miRNA is regulated by the available RNA targetome and predicts miRNA function. (Flores et al., 2014).

\section{Small RNA:target RNA binding single-molecule analysis}

Recent advances in single-molecule analysis brought also single- molecule data about RISC:target interaction, which is consistent with other biochemical data and the two state model for Argonaute action (Li and Zhang, 2012; Zander et al., 2014).

Loaded AGO2 utilizes short RNAs as specificity determinants with thermodynamic and kinetic properties more typical of RNA-binding proteins. A small RNA loaded on Argonaute does not follows rules by which free oligonucleotides find, bind, and dissociate from complementary nucleic acid sequences (Salomon et al., 2015). This is conceivable given the fixed "A" conformation of the seed of a small RNA loaded on an Argonaute protein.

Single-molecule fluorescence experiments using a minimal RISC (a small RNA and AGO2) showed that target binding starts at the seed region of the guide RNA (Chandradoss et al., 2015; Jo et al., 2015a; Jo et al., 2015b). AGO2 initially scans for target sites with complementarity to nucleotides $2-4$ of the miRNA. This initial transient interaction propagates into a stable association when target complementarity extends to nucleotides $2-8$. This stepwise recognition process is coupled to lateral diffusion of AGO2 along the target RNA, which promotes the target search by enhancing the retention of AGO2 on the RNA (Chandradoss et al., 2015). Stable RISC binding is thus efficiently established with the seed match only, providing a potential explanation for the seed-match rule of miRNA target selection (Chandradoss et al., 2015; Jo et al., 2015a; Jo et al., 2015b). Mouse AGO2 binds tighter to miRNA targets than its RNAi cleavage product, even though the cleaved product contains more base pairs (Salomon et al., 2015). Annealing between miRNA and its target with poor seed match proceeds in a stepwise way, which is in accordance with the increase in the number of conformational states of miRNA-target duplex accommodated by the miRISC, suggesting the structural plasticity of human miRISC to conciliate the mismatches in seed region (Li and Zhang, 2012)

Target cleavage required extensive sequence complementarity and accelerated coreRISC dissociation for recycling (Jo et al., 2015a) and sensitively depended on the sequence (Jo et al., 2015b). While RISC generally releases the 5' cleavage fragment from the guide 3 ' supplementary region first and then the 3 ' fragment from the seed region. This order can be reversed by extreme stabilization of the 3' supplementary region or mismatches in the seed region. Therefore, the release order of the two cleavage fragments is influenced by the 
stability in each region, in contrast to the unidirectional base pairing propagation from the seed to the 3' supplementary region upon target recognition.(Yao et al., 2015).

\section{Off-targeting - causes and remedies}

Off-targeting effects surfaced as a major issue in RNAi experiments when the effects of RNAi treatment were systematically analyzed (Fedorov et al., 2006; Jackson et al., 2003; Lin et al., 2005; Scacheri et al., 2004; Snove and Holen, 2004). One of the most revealing data came from mammalian cells transfected with different siRNAs targeting the same gene, which were systematically analyzed using microarrays (Jackson et al., 2003). Using 16 different siRNAs against IGF1R and 8 different siRNAs against MAPK14, strong siRNA-specific expression changes were found in transfected cells with only a few genes regulated in common by siRNAs targeting the same gene. Off-targeting effects were also found also in other animal models (Ma et al., 2006) and plants (Xu et al., 2006). In fact, off-targeting causes a significant bias in high-throughput RNAi screens (Ma et al., 2006)

Off-targeting is concentration dependent, it could be attributed to both siRNA strands, and a portion of off-targeting appears to be caused by partial complementarity between a siRNA and its target, reminiscent of the 5' seed regions of miRNAs (Aleman et al., 2007; Birmingham et al., 2006; Jackson et al., 2003; Jackson et al., 2006b; Qiu et al., 2007). In some cases of off-targeting, no correlation between predicted and actual off-target effects was reported (Hanning et al., 2013). However, this probably reflects problems of accurate miRNA target prediction rather than the absence of miRNA-like off-targeting. In any case, a recent systematic analysis of off-targeting effects confirmed that strength of base pairing in the siRNA seed region is the primary factor determining the efficiency of off-target silencing (Kamola et al., 2015)

The main cause of off-targeting is miRNA-like behavior of siRNAs. It was experimentally demonstrated in mammalian cells that siRNAs can function as miRNAs (Doench et al., 2003) and that siRNAs imperfectly matching endogenous mRNAs repress translation (Martin and Caplen, 2006; Saxena et al., 2003) suggesting that miRNAs and siRNAs use similar if not identical, mechanisms for target repression (Zeng et al., 2003). The current view of mammalian RNAi is that experimental RNAi induced with a siRNA or shRNA hijacks the molecular machinery dedicated to the miRNA pathway (reviewed in Svoboda, 2014). Consequently, some degree of off-targeting likely occurs in every RNAi experiment.

Importantly, experimental RNAi can also cause artifacts through saturation of the miRNA pathway, which essentially suppresses normal miRNA function (Khan et al., 2009). Exportin 5 seems to be a bottleneck for an effective RNA silencing (Lu and Cullen, 2004; Yi et al., 2005). Indeed, lethal non-specific effects observed with type I shRNAs delivered to the mouse liver by a viral vector were linked to the saturation of Exportin 5 (Grimm et al., 2006). Inhibition of Exportin 5 could also provide an explanation to early lethality defects observed during generation transgenic mice carrying class I shRNA expression cassette (Cao et al., 2005). 


\section{Suppression and by-passing off-targeting}

Off-targeting has been a recurring problem with RNAi experiments, especially in RNAi screens searching for novel regulators. Off-targeting was frequently causing false-positive results in such screens although this issue has been partially remedied (reviewed in Mohr et al., 2014; Petri and Meister, 2013). Below, I list options for dealing with off-targeting, which emerged from the literature review.

\section{Appropriate experimental design}

This is actually a simple solution, which emerged from initial experiments detecting off-targeting (reviewed in(Svoboda, 2007), which suggested that off-targeting operates through miRNA-like behavior of siRNAs and is concentration-dependent. Thus, a proper practice is to use the minimal effective siRNA concentration. Importantly, this step strongly reduces off-targeting but it does not eliminate it as the targeting siRNA is still present and functions as a miRNA (Jackson et al., 2003; Jackson et al., 2006b).

\section{Pools of SiRNA}

An extension of a strategy to lower siRNA concentration to the point that off-targeting effects in the model system become very low or even undetectable. If a pool of 10 siRNAs is used at the same total siRNA concentration, a single siRNA is having ten times lower concentration and causes lower off-targeting effects. One can produce an siRNA pool by an enzymatic digest of long dsRNA with Dicer or simply purchase a number of siRNAs targeting a single mRNA. In fact, some companies offer pre-made siRNA pools. A unique type of siRNA pools are siPools, which are produced by in vitro transcription of tandemly arrayed siRNA sequences (Hannus et al., 2014)

\section{Bioinformatics filtering}

Since the siRNA seed region is strongly associated with off-target silencing (Jackson et al., 2006b; Kamola et al., 2015), it could be used to filter RNAi screening data to reduce of off-target rates (Yilmazel et al., 2014; Zhong et al., 2014). In fact, revised analysis of RNAi screens could identify functionally relevant genes suppressed by off-targeting (Adams et al., 2015; Lin et al., 2007; Singh et al., 2015).

\section{Better small RNA design}

Understanding of the molecular mechanism of RNAi is also reflected in constantly improving siRNA design which aims at providing siRNAs specifically silencing a gene of interest with little or no off-target effects and no cell toxicity (reviewed in Ahmed et al., 2015; Tafer, 2014). Improved siRNA design can reduce off-targeting in several ways. First, siRNAs designed for efficient strand selection would have reduced off-targeting caused by AGO-loaded passenger strand. It was also found that increased siRNA duplex stability 
correlates with reduced off-target and elevated on-target effects (Petri et al., 2011). This can be, for example, influenced by the seed binding energy and seed composition, which would determine the pool of potential binding sites in the transcriptome and the difference between on-target and off-target RNAs (Das et al., 2013a; Das et al., 2013b). Adaptations of siRNA/shRNA design to reduce off-target effects include weak base pairing in both seed and 3 ' regions (Gu et al., 2014) and evaluation of potential cross-hybridization candidates (Anderson et al., 2008; Yamada and Morishita, 2005). Reduced off-targeting features were subsequently integrated into siRNA design tools such as siDirect (Naito and Ui-Tei, 2013; Naito et al., 2009).

\section{Mismatch introduction}

Mismatch introduction into siRNA at the positions 2 of the base pairing also weakens off-targeting (Dua et al., 2011; Li et al., 2015)

\section{Chemical modifications of small RNAs}

The discovery that off-targeting involves miRNA-like behavior of siRNAs prompted research on chemical modifications that would reduce miRNA-like behavior while not interfering with desired RNAi effects (Chiu and Rana, 2003). A thorough review of the chemical modifications is beyond the scope of this report but can be found elsewhere (Engels, 2013; Nolte et al., 2013; Peacock et al., 2011; Snove and Rossi, 2006). There are two common strategies, to reduce off-targeting - (I) Chemical modifications on the passenger strand preventing its loading, hence eliminating off-targeting caused by the passenger strand (Chen et al., 2008; Snead et al., 2013) and (II) Chemical modifications in the seed region, which interfere with miRNA-like target recognition but do not prevent specific RNAi targeting. Different chemistry was used for chemical modification of siRNAs with reduced off-targeting effects including unlocked nucleic acid (UNA) modification (Snead et al., 2013), locked nucleic acid (LNA) modification (Fluiter et al., 2009), 2'-O-methyl ribosyl (Chen et al., 2008; Jackson et al., 2006a), or abasic nucleotides (Seok et al., 2016b).

Position of the modification on the guiding strand is important for reduced off-targeting. While it is usually involving seed, the modified nucleotide may vary. For example, 2'-O-methyl ribosyl substitution at position 2 in the guide strand reduces most off-target effects caused by complementarity to the seed region of the siRNA guide strand (Jackson et al., 2006a). At the same time, an abasic nucleotide at the position 6 in the guide strand also eliminates miRNA-like off-target repression but preserves near-perfect on-target activity (80-100\%) (Seok et al., 2016b).

\section{Discerning specific RNAi phenotypes from off-targeting effects}

While strategies for suppressing off-targeting effects clearly reduce experimental artifacts, off-targeting should be seen as a type of noise in RNAi experiments that cannot be completely eliminated. Assuming that some off-targeting occurs in every RNAi experiment, one can focus on a more important issue: how to identify biologically relevant effects 
of off-targeting (phenotype) and separate them from the specific RNAi effect caused by knock-down of the desired gene. The idea is simple - while one can try to minimize off-targeting effects, the risk cannot be completely eliminated. Thus, it is equally important to use an appropriate experimental design, which allows to distinguish between off-targeting and specific RNAi effects. The two possible strategies were proposed a decade ago and were named "the two R's": rescue and redundancy (Echeverri et al., 2006).

The principle of the rescue strategy is expressing an RNAi-resistant version of the targeted gene. If a phenotype is caused by the gene knock-down, it should be rescued. It can be either mutated such that the base pairing with a short RNA is eliminated. One can, for example target 3'UTR and use a different one in the rescue construct or mutate/degenerate appropriate codon positions if targeting CDS. This strategy is powerful because it accepts all effects in an RNAi experiment and tests the contribution of the specific gene knock-down. For recent information on design of the rescue system see, for example, (Kumar, 2015)

The second strategy is based on phenotype redundancy. Two or more RNAi triggers with different sequences (i.e. specific siRNAs or shRNAs) producing the same phenotype decrease the probability that a phenotype would be caused by off-targeting. However, some common phenotypes (e.g. slower growth, apoptosis, and developmental arrest) may be a frequent off-targeting phenotype induced by different RNAi triggers, so the redundancy strategy would be less powerful than the rescue strategy described above. However, for some purposes (e.g. high-throughput RNAi screening), it might be easier to implement the redundancy strategy as a control for off-targeting than the rescue strategy.

Importantly, "non-targeting" controls (e.g. siRNAs with a random sequence or targeting non-expressed genes such as EGFP or luciferase) cannot be used controls for off-targeting for reasons mentioned above. It is a frequent misconception ignoring the fact that off-targeting is individual to each RNAi trigger because it is sequence-specific. "Non-targeting" siRNAs or shRNAs RNAs may serve as controls for the sequence-independent effects, such as interferon response and saturation of RNA silencing with an excess of exogenous short RNAs. If a small RNA is needed as a control for off-targeting, one may only use a pool of scrambled small RNAs, which would have highly diluted off-targeting effects.

\section{Target identification - in silico \& experimental approaches}

Target identification is a common issue in the small RNA field (reviewed for example in Pasquinelli, 2012; Tarang and Weston, 2014). Target identification can utilize bioinformatic analysis, experimental analysis or their combination. Briefly, bioinformatic analysis primarily implements the canonical seed-match model, evolutionary conservation, and binding energy, which are often complemented by neural networks trained on sets of experimental data in order to optimize filtering parameters. Some bioinformatics tools also consider non-canonical binding sites. Importantly, a mere presence of a miRNA binding site is insufficient for predicting target regulation as additional factors influence the regulation, including the above-mentioned accessibility of a binding site and stoichiometry between a miRNA and its targets. In the end, experimental verification of microRNA targets is essential, prediction alone is insufficient (Law et al., 2013). 


\section{Target prediction in silico}

Identification of many miRNAs in model organisms prompted development of bioinformatics tools for prediction of targeted mRNAs (Enright et al., 2003; Grun et al., 2005; John et al., 2004; Kiriakidou et al., 2004; Krek et al., 2005; Lewis et al., 2003; Stark et al., 2003). A number of bioinformatics tools emerged for miRNA analysis and target prediction (a comprehensive overview of all miRNA analysis tools is provided at https://tools4mirs .org/, for recent reviews on bioinformatic target prediction see, for example, (Elton and Yalowich, 2015; Lagana, 2015; Li and Zhang, 2015; Ristevski, 2015). A searchable database of systematically annotated miRNA tools can be found here: https://tools4mirs.org /software/target_prediction/.

Importantly, accurate bioinformatic prediction of miRNA-mediated repression is still problematic. This was shown, for example, during experiments with systematically generated artificial miRNAs targeting a desired gene (Arroyo et al., 2014). It turned out that seed-based artificial miRNA design was highly inefficient, as the majority of miRNAs with even perfect seed matches did not repress either target. Moreover, commonly used target prediction programs had problems to discriminate effective artificial miRNAs from ineffective ones, indicating that current algorithms do not fully accommodate important miRNA features allowing for designing artificial miRNAs (Arroyo et al., 2014). Another unresolved issue is reliable prediction of non-canonical (non-seed) miRNA binding sites as most algorithms are based on detection of seed-based miRNA binding sites.

\section{Common target prediction tools for animal miRNAs}

Among the prediction tools, several can be highlighted. These include Targetscan, miRanda, DIANA-microT, PicTAR, whose predictions were integrated into the miRBase, the central annotation database for miRNAs (Kozomara and Griffiths-Jones, 2014) and were also repeatedly evaluated in benchmark studies (Alexiou et al., 2009; Ding et al., 2012; Majoros et al., 2013; Peterson et al., 2014; Xu et al., 2014a). I add to these also MIRZA as it is one of the most recent algorithms, which in many aspects outperforms the other ones (Gumienny and Zavolan, 2015).

\section{Targetscan (http://www.targetscan.org/vert_71/)}

Targetscan is one of the most popular miRNA target prediction tools and its predictions are integrated in the miRBase (Kozomara and Griffiths-Jones, 2014). It is being developed in David Bartel's laboratory as a tool for miRNA target prediction for over a decade (Lewis et al., 2005; Lewis et al., 2003). It predicts biological targets of miRNAs by searching for the presence of conserved $8 \mathrm{mer}, 7 \mathrm{mer}$, and $6 \mathrm{mer}$ sites that match the seed region of each miRNA but there is also an optional search for poorly conserved sites. Its development included also scoring for binding sites with mismatches in the seed region that are compensated by 3' end pairing (Friedman et al., 2009) an improved quantitative model of canonical targeting (Agarwal et al., 2015) and addition other features. The current version considers a site type and fourteen other features and, according to authors, 
it outperforms other tools and matches high-throughput in vivo crosslinking approaches (Agarwal et al., 2015).

\section{DIANA-MicroT (http://diana.imis.athena-innovation.gr/DianaTools/index.php)}

DIANA-MicroT target prediction tools are another popular source for miRNA target prediction whose predictions are integrated with miRBase (Kozomara and Griffiths-Jones, 2014). DIANA-MicroT tools are being developed in Artemis Hatzigeorgiou's laboratory for over a decade (Alexiou et al., 2010; Kiriakidou et al., 2004; Maragkakis et al., 2009; Maragkakis et al., 2011; Megraw et al., 2007; Paraskevopoulou et al., 2013a; Paraskevopoulou et al., 2013b; Paraskevopoulou et al., 2016; Reczko et al., 2011; Sethupathy et al., 2006; Vergoulis et al., 2012; Vlachos et al., 2012). MicroT is specifically trained on a positive and a negative set of miRNA binding sites located in 3'-UTR and CDS regions. DIANA Tools offer target prediction algorithms (microT $\mathrm{v} 4$ and microT-CDS), databases of experimentally verified miRNA targets on coding and non-coding RNAs (TarBase v7.0 and LncBase), and tools for assessment of biological impacts of miRNAs (mirPath). In addition, the Web Server (v5.0) supports workflows enabling to perform complex functional miRNA analyses.

\section{Pictar (http://www.pictar.org/)}

Pictar is an algorithm for the identification of microRNA targets from Nikolaus Rajewsky's laboratory (Grun et al., 2005; Krek et al., 2005). Its predictions are also integrated with miRBase (Kozomara and Griffiths-Jones, 2014). Pictar offers for searching of targets of annotated miRNAs or mRNAs. Pictar predicts targets based on complementarity in a $7 \mathrm{nt}$ seed region, takes into account conservation and uses hidden Markov model approach to produce the final score. In contrast to Targetscan and DIANA-MicroT, Pictar has not been intensely developed. While it represents one of the older and simpler target prediction algorithms it is quite accurate prediction tool (Alexiou et al., 2009).

\section{miRanda at microRNA.org - Targets and Expression (http://www.microrna.org/)}

miRanda belongs among the pioneering target prediction algorithms (Enright et al., 2003; John et al., 2004). Its latest version miRanda-miRSVR (Betel et al., 2010; Betel et al., 2008) is integrated into target predictions at http://www.microrna.org where one can search predictions for annotated miRNAs in the main experimental model organisms. These predictions are also integrated with miRBase (Kozomara and Griffiths-Jones, 2014). miRanda analyses miRNA sequence complementarity with 3'UTRs and evaluates binding energy, conservation and binding site position in the 3'UTR. miRanda-miRSVR also identifies non-canonical and non-conserved sites (Betel et al., 2010; Betel et al., 2008).

\section{MIRZA \& MIRZA-G (http://www.sib.swiss/zavolan-mihaela/services)}

These tools are being developed in Mihaela Zavolan's lab and can be used for the prediction of miRNA targets and siRNA off-targets on a genome-wide scale. MIRZA is biophysical 
model of microRNA-target interaction that enables accurate identification of microRNA targets, particularly from Argonaute-CLIP data (Khorshid et al., 2013). MIRZA-G employs both the MIRZA biophysical model as well as other features to predict microRNA target sites genome-wide (Gumienny and Zavolan, 2015). MIRZA-G performed better on a benchmark test than Targetscan Context+ and DIANA-microT-v3 (Gumienny and Zavolan, 2015) making it a good choice for predicting canonical and non-canonical miRNA target sites as well as siRNA off-target sites.

\section{Target prediction for plant miRNAs}

Target prediction for plant miRNAs differs from prediction of miRNA targets in animals because of frequent highly complementary targets of plant miRNAs. A pioneering study of miRNA-mediated repression in plants revealed near-perfect complementarity between Arabidopsis miRNAs and their targets suggests suggesting that many plant miRNAs act similarly to siRNAs and direct mRNA cleavage (Rhoades et al., 2002). Consequently, miRNA target prediction in plants (for a recent review, see, for example, (Mishra et al., 2015)) is routinely performed as a relatively simple search for highly complementary mRNA sequences without a specialized target prediction algorithm. For example, Singh et al. (Singh et al., 2016) used for miRNA target prediction in ginger (Zingiber officinale) the following three simple criteria, which could be written into a simple search script:

1) not more than four mismatches allowed between predicted mRNAs and target gene.

2) no mismatches allowed for 10th and 11th positions of complementary site (a cleavage site).

3) maximum $4 \mathrm{GU}$ pair was allowed in the complimentary alignment.

Some authors even use for searching sequence similarity between a plant miRNA and mRNAs the Basic Local Alignment Search Tool algorithm (Huang et al., 2014a). A specific plant-miRNA-target analysis server is psRNATarget: a plant small RNA target analysis server (Dai and Zhao, 2011), which can be used not only for miRNAs but also for other plant small RNA analysis (Guzman et al., 2013; Huang et al., 2014b; Kumar et al., 2014). Other authors use general target prediction algorithms such as Miranda or RNAhybrid either alone (Shweta and Khan, 2014) or in more complex arrangements (Kurubanjerdjit et al., 2013).

A systematic evaluation of tools to predict targets of miRNAs and siRNAs in plants was provided by Srivastava et al. who compared 11 computational tools in identifying genomewide targets in Arabidopsis and other plants. Among them, Targetfinder was the most efficient in predicting 'true-positive' targets in Arabidopsis miRNA-mRNA interactions but performed much worse when analyzing data from non-Arabidopsis species. (Srivastava et al., 2014). Furthermore, combination of Targetfinder and psRNATarget provides high true positive coverage, whereas the intersection of psRNATarget and Tapirhybrid outputs deliver highly 'precise' predictions. All evaluated tools yielded a large number of 'false negative' predictions in non-Arabidopsis datasets (Srivastava et al., 2014).

Targets of plant miRNAs, that induce sequence-specific RNAi-like cleavage, can be further identified by employing degradome sequencing, a method determining RNA termini. 
Thus, in mRNAs cleaved by a miRNA after its $10^{\text {th }}$ nucleotide, one would observe alignment of RNA termini matching the predicted miRNA binding site. This strategy complementing bioinformatics description is further described in the following section.

\section{Common experimental approaches for identification of targets of small RNAs}

Bioinformatic target prediction is probabilistic. In other words, bioinformatics predictions identifies a set of putative small RNA targets, which fit certain set of criteria and are assigned a certain probability of being targeted by a specific small RNA. At the same time, each prediction yields positive and false negative results. A common problem in bioinformatic prediction is reliable prediction of non-canonical targets, whose recognition does not involve a complete seed match and, to a lesser extent, prediction of targets recognized through non-conserved binding sites. It is common that researchers aiming at target identification start with bioinformatics prediction and become entangled in the net of prediction tools and generate partially overlapping lists of predicted targets. This strategy is inherently biased towards canonical conserved miRNA binding sites and the highest scoring targets will have more than one such a site. However, this strategy is problematic for identification of the full set of targets.

Accordingly, more reliable identification of small RNA targets usually combines bioinformatics and experimental approaches. (Chen et al., 2015; Tarang and Weston, 2014; Thomson et al., 2011).

\section{High throughput expression analysis}

High throughput analysis (expression arrays, RNA sequencing or high-throughput proteomics) can complement target prediction in different ways. One can manipulate the miRNA pathway by various means (reviewed, for example in Svoboda, 2015), such as miRNA overexpression, knock-out or inhibition by complementary oligonucleotides (so-called antagomirs) and then identify correlations between target prediction and their actual behavior (e.g. Krutzfeldt et al., 2005; Lim et al., 2005; Sood et al., 2006). However, these strategies yield only correlative results, i.e. do not directly detect smallRNA:targetRNA interaction.

\section{Small RNA capture strategies}

These strategies can be used to identify either mRNAs bound by a small RNA or small RNAs bound to a selected mRNA. Identification of targets of a small RNA employs delivery of a tagged small RNA (e.g. biotinylated miRNA) followed by an affinity capture to co-purify targets (Baigude et al., 2012; Orom and Lund, 2007; Tan and Lieberman, 2016). These strategies are prone to artifacts because delivery of biotinylated small RNAs can create nonphysiological conditions and affinity purification could be influenced by the binding site context.

Identification of small RNAs bound to a selected mRNA(e.g. miR-CATCH or miRIP methods) employs capture of a selected RNA with associated small RNA using a complementary 
oligonucleotide, which can be used for affinity capture (e.g. a biotinylated complementary oligonucleotide or a complementary oligonucleotide covalently bound to a magnetic bead) (Su et al., 2015; Vencken et al., 2015). This strategy is suitable for detailed analysis of miRNA-mediated regulation of a specific mRNA but not for a transcriptome-wide target assessment. One variant employs a tested mRNA fused with a common sequence (EGFP) allowing for using the same set of biotinylated DNA anti-sense oligonucleotides for analyzing different mRNAs allowing for increasing the throughput (Wei et al., 2014).

\section{miRNA extension}

This strategy employs miRNA extension with a reverse transcriptase on endogenous target mRNAs. Purified hybrid 3'-cDNA-miRNA-5' molecules are used in a second round of reverse transcription and sequenced (Vatolin et al., 2006). However, this method is prone to artifacts stemming from the variability of miRNA:target mRNA base pairing, which would result in highly variable efficiency of reverse transcription priming.

\section{Immunoprecipitation of small RNA:target RNA complexes}

There is a large number of immunoprecipitation strategies aimed at purifying small RNA:target RNA complexes, usually by immunoprecipitating them through an Argonaute protein. Initial experiments immunoprecipitated native Argonaute complexes without including a cross-linking step; immunopurified RNAs were analyzed on microarrays (Easow et al., 2007; Hendrickson et al., 2008; Karginov et al., 2007). An adaptation of Argonaute immunoprecipitation for detection of specific miRNA targets is a RIP competition assay wherein anti-miR is titrated into cytosolic extracts prior to Argonaute immunoprecipitation. Direct target transcripts displaced by anti-miR are then identified based on their depletion from IP fraction (Androsavich and Chau, 2014)

The immunoprecipitation strategy was further developed into a number of methods for isolation of small RNAs bound to their targets, which include high throughput sequencing of crosslinking immunoprecipitation (HITS-CLIP) and crosslinking ligation and sequencing of hybrids (CLASH) methods (reviewed more detail in Broughton and Pasquinelli, 2016; Jaskiewicz et al., 2012).

There are several modifications of the basic HITS-CLIP. An improvement of the basic HITS-CLIP approach (Chi et al., 2009; Zisoulis et al., 2010) came with crosslinking based on photoactivatable nucleosides such as 4-thiouridine, a CLIP modification known as photoactivatable-ribonucleoside-enhanced crosslinking and immunoprecipitation (PAR-CLIP) (Hafner et al., 2010; Hafner et al., 2012). PAR-CLIP offers more efficient crosslinking, hence up to three orders of magnitude better RNA recovery than HITS-CLIP (Hafner et al., 2010). Furthermore, PAR-CLIP also allows for precise localization of miRNA binding site as cross-linked 4-thiouridine marks the cross-linked site with frequent thymidine to cytidine change, which is revealed by deep sequencing (Hafner et al., 2010).

Another modified strategy is covalent ligation of endogenous Argonaute-bound RNAs crosslinking immunoprecipitation (CLEAR-CLIP) which enriches miRNAs ligated to their endogenous mRNA targets (Moore et al., 2015). CLEAR-CLIP approach is in principle 
the same as the above-mentioned CLASH (Helwak et al., 2013; Helwak and Tollervey, 2014). Adding ligation of miRNAs to their mRNA targets yields chimeric reads allowing for robust detection miRNA:target RNA interactions occurring in vivo.

Data mining of CLIP data provides not only a comprehensive list of miRNA:target mRNA interactions but also provides insights into the principles governing these interactions, which in turn facilitate further improvement of target prediction algorithms. For example, an in vivo C. elegans data set and reanalysis of published mammalian AGO-CLIP data yielded approximately 17,000 miRNA:target site interactions. This strategy identified canonical, noncanonical, and nonconserved miRNA:targets with about $80 \%$ of miRNA interactions having perfect or partial seed complementarity (Grosswendt et al., 2014). Another comprehensive analysis of 34 Argonaute HITS-CLIP datasets from human and mouse cells revealed that many heteroduplexes are "non-canonical" i.e. their seed region comprises G:U and bulge combinations (Clark et al., 2014).

CLIP strategies are nowadays popular for high-throughput analysis of physiological miRNA targets (Chi et al., 2012; Chi et al., 2009; Clark et al., 2014; Grosswendt et al., 2014; Haecker and Renne, 2014; Hafner et al., 2010; Imig et al., 2015; Leung et al., 2011; Liu et al., 2014a; Marin et al., 2012; Zisoulis et al., 2010) and it is accompanied with a number of algorithms and databases facilitating identification of miRNA targets in high-throughput CLIP data (Balaga et al., 2012; Bandyopadhyay et al., 2015; Chou et al., 2013; Erhard et al., 2013; Guo et al., 2015; Hsieh and Wang, 2011; Hsu et al., 2015; Liu et al., 2013; Paraskevopoulou et al., 2013a; Rennie et al., 2014; Wang et al., 2013; Wang et al., 2014; Xie et al., 2014; Yang et al., 2011).

\section{Degradome analysis}

It was mentioned above in the section discussing target prediction for plant miRNAs that when small RNA-target RNA interaction results in RNAi-like cleavage, identification of targets can be experimentally augmented by degradome sequencing. This sequencing allows for identification of RNA termini, including those created by RNAi-like cleavage. Thus, if there are mRNAs cleaved by a miRNA after its $10^{\text {th }}$ nucleotide, one would observe alignment of RNA termini matching the predicted miRNA binding site. Degradome analysis usually defines a category of transcripts predicted to be endonucleolytically cleaved and then are cleavage positions compared to predicted miRNA binding sites (Ding et al., 2016; Fan et al., 2016; Li and Sunkar, 2013; Shao et al., 2013; Wang et al., 2016; Xing et al., 2014). Degradome analysis and target prediction has been integrated in to a web resource comPARE for plant miRNA target analysis (Kakrana et al., 2014). Degradome analysis can be also used in animals to identify rare miRNA targets suppressed by slicing (Park et al., 2013).

\section{Conclusions}

Given the nature of the interaction between small RNAs and their target RNAs, target prediction will always yield putative targets with partial complementary. For seed-mediated interactions, there can easily be hundreds of targets predicted for any small RNA acting 
as a miRNA. This is due to the combination of the following facts: a) a specific hexamer sequence occurs in a random sequence with a theoretical frequency of 1/4096 and b) exons of protein-coding genes constitute 70-80 megabases of well-annotated mammalian genomes (and exome size of eukaryotic genomes might not be dramatically smaller than that). Therefore, a hexamer would occur in a mammalian exonic sequence on average $\sim 20$ $000 \mathrm{x}$ and if $1 \%$ of these hexamers would fit other target site prediction criteria, that would leave on average 200 potential binding sites.

The bottom line is that applying a minimal base pairing criterion for miRNA-like interaction will identify a number of potential targets in any eukaryotic organism. At the same time, sequence based target prediction is insufficient to assess whether there will be target repression induced by a specific small RNA when introduced into an animal or mammal because there is a number of other critical parameters, which must be considered. Two of them stand out above anything else: 1) the amount of the specific small RNA loaded on Argonaute proteins, and 2) target site accessibility. Thus, target assessment of small RNAs needs to address these two parameters. While target accessibility can be considered a relatively common feature for all organisms since the same rules would apply for RNA folding and interference caused by RNA binding proteins (translation machinery etc.), loading of a small RNA onto Argonaute proteins depends on factors which may dramatically differ between different organisms. For example, organisms that exhibit environmental RNAi would be much more prone to the uptake of small RNAs. Factors such as length, chemical modifications, or terminal nucleotides of a small RNA, could underlie differences in sorting and loading to the various Argonaute proteins. Thus, possible fates of a specific small RNA in a specific organism are difficult to predict and should be tested experimentally. The most informative parameter is the amount (number of molecules) of a small RNA in question, which would be loaded on an Argonaute protein (e.g. AGO1 and AGO2 in animals), because it could be compared with known kinetic data to assess the strength of potential repressive effects it could achieve in vivo.

\section{Acknowledgement}

I would like to thank my colleagues Jan Paces, Miloslav Nic, and Tomas Novotny for help with collecting literature for the review and Jana Kubikova for help with figure preparation. The review content was produced under a contract OC/EFSA/GMO/2015/01-CT 01 with European Food Safety Authority (EFSA); the opinions expressed are those of the contractor only and do not represent EFSA's official position. Publication of the review was funded by LO1220 and LM2015063 by the Ministry of Education, Youth and Sports.

\section{References}

Adams, R., Nicke, B., Pohlenz, H.D., and Sohler, F. (2015). Deciphering Seed Sequence Based Off-Target Effects in a Large-Scale RNAi Reporter Screen for E-Cadherin Expression. Plos One 10, e0137640-e0137640. 
Afonso-Grunz, F., and Muller, S. (2015). Principles of miRNA-mRNA interactions: beyond sequence complementarity. Cellular and Molecular Life Sciences 72, 3127-3141.

Agarwal, V., Bell, G.W., Nam, J.W., and Bartel, D.P. (2015). Predicting effective microRNA target sites in mammalian mRNAs. Elife 4.

Ahmed, F., Dai, X.B., and Zhao, P.X. (2015). Bioinformatics Tools for Achieving Better Gene Silencing in Plants. In Plant Gene Silencing: Methods and Protocols, pp. 43-60.

Aleman, L.M., Doench, J., and Sharp, P.A. (2007). Comparison of siRNA-induced off-target RNA and protein effects. Rna-a Publication of the Rna Society 13, 385-395.

Alexiou, P., Maragkakis, M., Papadopoulos, G.L., Reczko, M., and Hatzigeorgiou, A.G. (2009). Lost in translation: an assessment and perspective for computational microRNA target identification. Bioinformatics 25, 3049-3055.

Alexiou, P., Vergoulis, T., Gleditzsch, M., Prekas, G., Dalamagas, T., Megraw, M., Grosse, I., Sellis, T., and Hatzigeorgiou, A.G. (2010). miRGen 2.0: a database of microRNA genomic information and regulation. Nucleic Acids Research 38, D137-D141.

Allen, E., Xie, Z.X., Gustafson, A.M., Sung, G.H., Spatafora, J.W., and Carrington, J.C. (2004). Evolution of microRNA genes by inverted duplication of target gene sequences in Arabidopsis thaliana. Nature Genetics 36, 1282-1290.

Ameres, S.L., Martinez, J., and Schroeder, R. (2007). Molecular basis for target RNA recognition and cleavage by human RISC. Cell 130, 101-112.

Anderson, E.M., Birmingham, A., Baskerville, S., Reynolds, A., Maksimova, E., Leake, D., Fedorov, Y., Karpilow, J., and Khvorova, A. (2008). Experimental validation of the importance of seed complement frequency to siRNA specificity. Rna-a Publication of the Rna Society 14, 853-861.

Androsavich, J.R., and Chau, B.N. (2014). Non-inhibited miRNAs shape the cellular response to anti-miR. Nucleic Acids Research 42, 6945-6955.

Arroyo, J.D., Gallichotte, E.N., and Tewari, M. (2014). Systematic design and functional analysis of artificial microRNAs. Nucleic Acids Research 42, 6064-6077.

Axtell, M.J. (2013). Classification and comparison of small RNAs from plants. Annu Rev Plant Biol 64, 137-159.

Baigude, H., Ahsanullah, Li, Z., Zhou, Y., and Rana, T.M. (2012). miR-TRAP: a benchtop chemical biology strategy to identify microRNA targets. Angew Chem Int Ed Engl 51, 5880-5883.

Balaga, O., Friedman, Y., and Linial, M. (2012). Toward a combinatorial nature of microRNA regulation in human cells. Nucleic Acids Research 40, 9404-9416.

Bandyopadhyay, S., Ghosh, D., Mitra, R., and Zhao, Z.M. (2015). MBSTAR: multiple instance learning for predicting specific functional binding sites in microRNA targets. Scientific Reports $5,8004-8004$.

Bartel, D.P. (2009). MicroRNAs: Target Recognition and Regulatory Functions. Cell 136, 215-233.

Betel, D., Koppal, A., Agius, P., Sander, C., and Leslie, C. (2010). Comprehensive modeling of microRNA targets predicts functional non-conserved and non-canonical sites. Genome Biology 11, R90-R90.

Betel, D., Wilson, M., Gabow, A., Marks, D.S., and Sander, C. (2008). The microRNA.org resource: targets and expression. Nucleic Acids Research 36, D149-D153.

Bhandare, V., and Ramaswamy, A. (2016). Structural dynamics of human argonaute2 and its interaction with siRNAs designed to target mutant tdp43. Advances in Bioinformatics 2016, 8792814-8792814. 
Birmingham, A., Anderson, E.M., Reynolds, A., Ilsley-Tyree, D., Leake, D., Fedorov, Y., Baskerville, S., Maksimova, E., Robinson, K., Karpilow, J., et al. (2006). 3' UTR seed matches, but not overall identity, are associated with RNAi off-targets. Nature methods 3, 199-204.

Brennecke, J., Stark, A., Russell, R.B., and Cohen, S.M. (2005). Principles of MicroRNA-target recognition. Plos Biology 3, 404-418.

Broughton, J.P., and Pasquinelli, A.E. (2016). A tale of two sequences: microRNA-target chimeric reads. Genetics, selection, evolution : GSE 48, 31-31.

Brousse, C., Liu, Q.K., Beauclair, L., Deremetz, A., Axtell, M.J., and Bouche, N. (2014). A non-canonical plant microRNA target site. Nucleic Acids Research 42, 5270-5279.

Cao, W., Hunter, R., Strnatka, D., McQueen, C.A., and Erickson, R.P. (2005). DNA constructs designed to produce short hairpin, interfering RNAs in transgenic mice sometimes show early lethality and an interferon response. J Appl Genet 46, 217-225.

Chandradoss, S.D., Schirle, N.T., Szczepaniak, M., MacRae, I.J., and Joo, C. (2015). A Dynamic Search Process Underlies MicroRNA Targeting. Cell 162, 96-107.

Chen, L., Hou, J., and Liu, L. (2015). High-Throughput Techniques for Identifying microRNA Target Genes. Current Bioinformatics 10, 370-376.

Chen, P.Y., Weinmann, L., Gaidatzis, D., Pei, Y., Zavolan, M., Tuschl, T., and Meister, G. (2008). Strand-specific 5 '-O-methylation of siRNA duplexes controls guide strand selection and targeting specificity. Rna-a Publication of the Rna Society 14, 263-274.

Chi, S.W., Hannon, G.J., and Darnell, R.B. (2012). An alternative mode of microRNA target recognition. Nature Structural \& Molecular Biology 19, 321-U380.

Chi, S.W., Zang, J.B., Mele, A., and Darnell, R.B. (2009). Argonaute HITS-CLIP decodes microRNA-mRNA interaction maps. Nature 460, 479-486.

Chiu, Y.L., and Rana, T.M. (2003). siRNA function in RNAi: A chemical modification analysis. Rna-a Publication of the Rna Society 9, 1034-1048.

Chou, C.H., Lin, F.M., Chou, M.T., Hsu, S.D., Chang, T.H., Weng, S.L., Shrestha, S., Hsiao, C.C., Hung, J.H., and Huang, H.D. (2013). A computational approach for identifying microRNA-target interactions using high-throughput CLIP and PAR-CLIP sequencing. Bmc Genomics 14, S2-S2.

Cipolla, G.A. (2014). A non-canonical landscape of the microRNA system. Frontiers in genetics 5, 337-337.

Clark, P.M., Loher, P., Quann, K., Brody, J., Londin, E.R., and Rigoutsos, I. (2014). Argonaute CLIPSeq reveals miRNA targetome diversity across tissue types. Scientific Reports 4, 5947-5947.

Dai, X.B., and Zhao, P.X. (2011). psRNATarget: a plant small RNA target analysis server. Nucleic Acids Research 39, W155-W159.

Das, S., Ghosal, S., Chakrabarti, J., and Kozak, K. (2013a). SeedSeq: Off-Target Transcriptome Database. Biomed Research International 2013, 905429-905429.

Das, S., Ghosal, S., Kozak, K., and Chakrabarti, J. (2013b). An siRNA designing tool with a unique functional off-target filtering approach. Journal of Biomolecular Structure \& Dynamics 31, 1343-1357.

De, N., Young, L., Lau, P.W., Meisner, N.C., Morrissey, D.V., and MacRae, I.J. (2013). Highly Complementary Target RNAs Promote Release of Guide RNAs from Human Argonaute2. Molecular Cell 50, 344-355.

Deerberg, A., Willkomm, S., and Restle, T. (2013). Minimal mechanistic model of siRNA-dependent target RNA slicing by recombinant human Argonaute 2 protein. America 110, 17850-17855. 
Didiano, D., and Hobert, O. (2006). Perfect seed pairing is not a generally reliable predictor for miRNA-target interactions. Nature Structural \& Molecular Biology 13, 849-851.

Ding, J., Zhou, S., and Guan, J. (2012). Finding microRNA targets in plants: current status and perspectives. Genomics, proteomics \& bioinformatics 10, 264-275.

Ding, X.L., Li, J.J., Zhang, H., He, T.T., Han, S.H., Li, Y.W., Yang, S.P., and Gai, J.Y. (2016). Identification of miRNAs and their targets by high-throughput sequencing and degradome analysis in cytoplasmic male-sterile line NJCMS1A and its maintainer NJCMS1B of soybean. Bmc Genomics $17,24-24$.

Doench, J.G., Petersen, C.P., and Sharp, P.A. (2003). siRNAs can function as miRNAs. Genes \& Development $17,438-442$.

Du, Q., Thonberg, H., Wang, J., Wahlestedt, C., and Liang, Z.C. (2005). A systematic analysis of the silencing effects of an active siRNA at all single-nucleotide mismatched target sites. Nucleic Acids Research 33, 1671-1677.

Dua, P., Yoo, J.W., Kim, S., and Lee, D.K. (2011). Modified siRNA Structure With a Single Nucleotide Bulge Overcomes Conventional siRNA-mediated Off-target Silencing. Molecular Therapy 19, 1676-1687.

Easow, G., Teleman, A.A., and Cohen, S.M. (2007). Isolation of microRNA targets by miRNP immunopurification. Rna-a Publication of the Rna Society 13, 1198-1204.

Echeverri, C.J., Beachy, P.A., Baum, B., Boutros, M., Buchholz, F., Chanda, S.K., Downward, J., Ellenberg, J., Fraser, A.G., Hacohen, N., et al. (2006). Minimizing the risk of reporting false positives in large-scale RNAi screens. Nat Methods 3, 777-779.

Elkayam, E., Kuhn, C.D., Tocilj, A., Haase, A.D., Greene, E.M., Hannon, G.J., and Joshua-Tor, L. (2012). The structure of human argonaute-2 in complex with miR-20a. Cell 150, 100-110.

Ellwanger, D.C., Buttner, F.A., Mewes, H.W., and Stumpflen, V. (2011). The sufficient minimal set of miRNA seed types. Bioinformatics 27, 1346-1350.

Elton, T.S., and Yalowich, J.C. (2015). Experimental procedures to identify and validate specific mRNA targets of miRNAs. EXCLI journal 14, 758-790.

Engels, J.W. (2013). Gene silencing by chemically modified siRNAs. New Biotechnology 30, 302-307.

Enright, A.J., John, B., Gaul, U., Tuschl, T., Sander, C., and Marks, D.S. (2003). MicroRNA targets in Drosophila. Genome biology 5, R1-R1.

Erhard, F., Dolken, L., Jaskiewicz, L., and Zimmer, R. (2013). PARma: identification of microRNA target sites in AGO-PAR-CLIP data. Genome Biology 14, R79-R79.

Faehnle, C.R., Elkayam, E., Haase, A.D., Hannon, G.J., and Joshua-Tor, L. (2013). The making of a slicer: activation of human Argonaute-1. Cell Rep 3, 1901-1909.

Faehnle, C.R., and Joshua-Tor, L. (2007). Argonautes confront new small RNAs. Curr Opin Chem Biol 11, 569-577.

Fan, G.Q., Li, X.Y., Deng, M.J., Zhao, Z.L., and Yang, L. (2016). Comparative Analysis and Identification of miRNAs and Their Target Genes Responsive to Salt Stress in Diploid and Tetraploid Paulownia fortunei Seedlings. Plos One 11, e0149617-e0149617.

Fedorov, Y., Anderson, E.M., Birmingham, A., Reynolds, A., Karpilow, J., Robinson, K., Leake, D., Marshall, W.S., and Khvorova, A. (2006). Off-target effects by siRNA can induce toxic phenotype. Rna-a Publication of the Rna Society 12, 1188-1196. 
Flores, O., Kennedy, E.M., Skalsky, R.L., and Cullen, B.R. (2014). Differential RISC association of endogenous human microRNAs predicts their inhibitory potential. Nucleic Acids Research 42, 4629-4639.

Fluiter, K., Mook, O.R.F., and Baas, F. (2009). The Therapeutic Potential of LNA-Modified siRNAs: Reduction of Off-Target Effects by Chemical Modification of the siRNA Sequence. In Methods in Molecular Biology, pp. 189-203.

Friedman, R.C., Farh, K.K.H., Burge, C.B., and Bartel, D.P. (2009). Most mammalian mRNAs are conserved targets of microRNAs. Genome Research 19, 92-105.

Gan, H.H., and Gunsalus, K.C. (2015). Assembly and analysis of eukaryotic Argonaute-RNA complexes in microRNA-target recognition. Nucleic Acids Research 43, 9613-9625.

Grimm, D., Streetz, K.L., Jopling, C.L., Storm, T.A., Pandey, K., Davis, C.R., Marion, P., Salazar, F., and Kay, M.A. (2006). Fatality in mice due to oversaturation of cellular microRNA/short hairpin RNA pathways. Nature 441, 537-541.

Grimson, A., Farh, K.K.H., Johnston, W.K., Garrett-Engele, P., Lim, L.P., and Bartel, D.P. (2007). MicroRNA targeting specificity in mammals: Determinants beyond seed pairing. Molecular Cell 27, 91-105.

Grosswendt, S., Filipchyk, A., Manzano, M., Klironomos, F., Schilling, M., Herzog, M., Gottwein, E., and Rajewsky, N. (2014). Unambiguous Identification of miRNA: Target Site Interactions by Different Types of Ligation Reactions. Molecular Cell 54, 1042-1054.

Grun, D., Wang, Y.L., Langenberger, D., Gunsalus, K.C., and Rajewsky, N. (2005). MicroRNA target predictions across seven Drosophila species and comparison to mammalian targets. Plos Computational Biology 1, 51-66.

Gu, S., Zhang, Y., Jin, L., Huang, Y., Zhang, F.J., Bassik, M.C., Kampmann, M., and Kay, M.A. (2014). Weak base pairing in both seed and 3 ' regions reduces RNAi off-targets and enhances si/ shRNA designs. Nucleic Acids Research 42, 12169-12176.

Gumienny, R., and Zavolan, M. (2015). Accurate transcriptome-wide prediction of microRNA targets and small interfering RNA off-targets with MIRZA-G. Nucleic Acids Research 43, 1380-1391.

Guo, Z.W., Xie, C., Yang, J.R., Li, J.H., Yang, J.H., and Zheng, L.M. (2015). MtiBase: a database for decoding microRNA target sites located within CDS and 5 ' UTR regions from CLIP-Seq and expression profile datasets. Database-the Journal of Biological Databases and Curation 2015.

Guzman, F., Almerao, M.P., Korbes, A.P., Christoff, A.P., Zanella, C.M., Bered, F., and Margis, R. (2013). Identification of potential miRNAs and their targets in Vriesea carinata (Poales, Bromeliaceae). Plant Science 210, 214-223.

Haecker, I., and Renne, R. (2014). HITS-CLIP and PAR-CLIP advance viral miRNA targetome analysis. Critical Reviews in Eukaryotic Gene Expression 24, 101-116.

Hafner, M., Landthaler, M., Burger, L., Khorshid, M., Hausser, J., Berninger, P., Rothballer, A., Ascano, M., Jr., Jungkamp, A.C., Munschauer, M., et al. (2010). Transcriptome-wide identification of RNA-binding protein and microRNA target sites by PAR-CLIP. Cell 141, 129-141.

Hafner, M., Lianoglou, S., Tuschl, T., and Betel, D. (2012). Genome-wide identification of miRNA targets by PAR-CLIP. Methods 58, 94-105.

Haley, B., and Zamore, P.D. (2004). Kinetic analysis of the RNAi enzyme complex. Nature Structural \& Molecular Biology 11, 599-606.

Hanning, J.E., Saini, H.K., Murray, M.J., van Dongen, S., Davis, M.P.A., Barker, E.M., Ward, D.M., Scarpini, C.G., Enright, A.J., Pett, M.R., et al. (2013). Lack of correlation between predicted and 
actual off-target effects of short-interfering RNAs targeting the human papillomavirus type 16 E7 oncogene. British Journal of Cancer 108, 450-460.

Hannus, M., Beitzinger, M., Engelmann, J.C., Weickert, M.T., Spang, R., Hannus, S., and Meister, G. (2014). siPools: highly complex but accurately defined siRNA pools eliminate off-target effects. Nucleic Acids Research 42, 8049-8061.

Heale, B.S.E., Soifer, H.S., Bowers, C., and Rossi, J.J. (2005). siRNA target site secondary structure predictions using local stable substructures. Nucleic Acids Research 33, 1-10.

Heale, B.S.E., Soifer, H.S., Bowers, C., and Rossi, J.J. (2006). siRNA target site secondary structure predictions using local stable substructures (vol 33, pg 30, 2005). Nucleic Acids Research 34, 4653-4653.

Helwak, A., Kudla, G., Dudnakova, T., and Tollervey, D. (2013). Mapping the Human miRNA Interactome by CLASH Reveals Frequent Noncanonical Binding. Cell 153, 654-665.

Helwak, A., and Tollervey, D. (2014). Mapping the miRNA interactome by cross-linking ligation and sequencing of hybrids (CLASH). Nature Protocols 9, 711-728.

Hendrickson, D.G., Hogan, D.J., Herschlag, D., Ferrell, J.E., and Brown, P.O. (2008). Systematic Identification of mRNAs Recruited to Argonaute 2 by Specific microRNAs and Corresponding Changes in Transcript Abundance. Plos One 3, e2126-e2126.

Hill, C.G., Jabbari, N., Matyunina, L.V., and McDonald, J.F. (2014). Functional and Evolutionary Significance of Human MicroRNA Seed Region Mutations. Plos One 9, e115241-e115241.

Holen, T., Moe, S.E., Sorbo, J.G., Meza, T.J., Ottersen, O.P., and Klungland, A. (2005). Tolerated wobble mutations in siRNAs decrease specificity, but can enhance activity in vivo. Nucleic Acids Research 33, 4704-4710.

Hon, L.S., and Zhang, Z.M. (2007). The roles of binding site arrangement and combinatorial targeting in microRNA repression of gene expression. Genome Biology 8, R166-R166.

Hsieh, W.J., and Wang, H.Y. (2011). Human microRNA target identification by RRSM. Journal of Theoretical Biology 286, 79-84.

Hsu, S.D., Huang, H.Y., Chou, C.H., Sun, Y.M., Hsu, M.T., and Tsou, A.P. (2015). Integrated analyses to reconstruct microRNA-mediated regulatory networks in mouse liver using high-throughput profiling. Bmc Genomics 16, S12-S12.

Huang, Y., Zou, Q., Sun, X.H., and Zhao, L.P. (2014a). Computational Identification of MicroRNAs and Their Targets in Perennial Ryegrass (Lolium perenne). Applied Biochemistry and Biotechnology 173, 1011-1022.

Huang, Y., Zou, Q., and Wang, Z.B. (2014b). Computational identification of miRNA genes and their targets in mulberry. Russian Journal of Plant Physiology 61, 537-542.

Imig, J., Brunschweiger, A., Brummer, A., Guennewig, B., Mittal, N., Kishore, S., Tsikrika, P., Gerber, A.P., Zavolan, M., and Hall, J. (2015). miR-CLIP capture of a miRNA targetome uncovers a lincRNA H19-miR-106a interaction. Nature Chemical Biology 11, 107-U143.

Jackson, A.L., Bartz, S.R., Schelter, J., Kobayashi, S.V., Burchard, J., Mao, M., Li, B., Cavet, G., and Linsley, P.S. (2003). Expression profiling reveals off-target gene regulation by RNAi. Nature Biotechnology 21, 635-637.

Jackson, A.L., Burchard, J., Leake, D., Reynolds, A., Schelter, J., Guo, J., Johnson, J.M., Lim, L., Karpilow, J., Nichols, K., et al. (2006a). Position-specific chemical modification of siRNAs reduces "off-target" transcript silencing. Rna-a Publication of the Rna Society 12, 1197-1205. 
Jackson, A.L., Burchard, J., Schelter, J., Chau, B.N., Cleary, M., Lim, L., and Linsley, P.S. (2006b). Widespread siRNA “off-target” transcript silencing mediated by seed region sequence complementarity. Rna-a Publication of the Rna Society 12, 1179-1187.

Jagla, B., Aulner, N., Kelly, P.D., Song, D., Volchuk, A., Zatorski, A., Shum, D., Mayer, T., De Angelis, D.A., Ouerfelli, O., et al. (2005). Sequence characteristics of functional siRNAs. Rna-a Publication of the Rna Society 11, 864-872.

Janas, M.M., Wang, B., Harris, A.S., Aguiar, M., Shaffer, J.M., Subrahmanyam, Y.V., Behlke, M.A., Wucherpfennig, K.W., Gygi, S.P., Gagnon, E., et al. (2012). Alternative RISC assembly: binding and repression of microRNA-mRNA duplexes by human Ago proteins. RNA 18, 2041-2055.

Jaskiewicz, L., Bilen, B., Hausser, J., and Zavolan, M. (2012). Argonaute CLIP - A method to identify in vivo targets of miRINAs. Methods 58, 106-112.

Jo, M.H., Shin, S., Jung, S.R., Kim, E., Song, J.J., and Hohng, S. (2015a). Human Argonaute 2 Has Diverse Reaction Pathways on Target RNAs. Molecular Cell 59, 117-124.

Jo, M.H., Song, J.-J., and Hohng, S. (2015b). Single-molecule fluorescence measurements reveal the reaction mechanisms of the core-RISC, composed of human Argonaute 2 and a guide RNA. BMB Reports 48, 643-644.

John, B., Enright, A.J., Aravin, A., Tuschl, T., Sander, C., and Marks, D.S. (2004). Human MicroRNA targets. Plos Biology 2, 1862-1879.

Jones-Rhoades, M.W., and Bartel, D.P. (2004). Computational identification of plant microRNAs and their targets, including a stress-induced miRNA. Mol Cell 14, 787-799.

Jones-Rhoades, M.W., Bartel, D.P., and Bartel, B. (2006). MicroRNAS and their regulatory roles in plants. Annu Rev Plant Biol 57, 19-53.

Kakrana, A., Hammond, R., Patel, P., Nakano, M., and Meyers, B.C. (2014). sPARTA: a parallelized pipeline for integrated analysis of plant miRNA and cleaved mRNA data sets, including new miRNA target-identification software. Nucleic Acids Research 42, e139-e139.

Kamola, P.J., Nakano, Y., Takahashi, T., Wilson, P.A., and Uitei, K. (2015). The siRNA Non-seed Region and Its Target Sequences Are Auxiliary Determinants of Off-Target Effects. Plos Computational Biology 11, e1004656-e1004656.

Karginov, F.V., Conaco, C., Xuan, Z., Schmidt, B.H., Parker, J.S., Mandel, G., and Hannon, G.J. (2007). A biochemical approach to identifying microRNA targets. America 104, 19291-19296.

Katoh, T., and Suzuki, T. (2007). Specific residues at every third position of siRNA shape its efficient RNAi activity. Nucleic Acids Research 35, e27-e27.

Kertesz, M., Iovino, N., Unnerstall, U., Gaul, U., and Segal, E. (2007). The role of site accessibility in microRNA target recognition. Nature Genetics 39, 1278-1284.

Khan, A.A., Betel, D., Miller, M.L., Sander, C., Leslie, C.S., and Marks, D.S. (2009). Transfection of small RNAs globally perturbs gene regulation by endogenous microRNAs. Nature Biotechnology 27, 549-U592.

Khorshid, M., Hausser, J., Zavolan, M., and Van Nimwegen, E. (2013). A biophysical miRNA-mRNA interaction model infers canonical and noncanonical targets. Nature Methods 10, 253-255.

Kiriakidou, M., Nelson, P.T., Kouranov, A., Fitziev, P., Bouyioukos, C., Mourelatos, Z., and Hatzigeorgiou, A. (2004). A combined computational-experimental approach predicts human microRNA targets. Genes \& Development 18, 1165-1178.

Kozomara, A., and Griffiths-Jones, S. (2014). miRBase: annotating high confidence microRNAs using deep sequencing data. Nucleic Acids Res 42, D68-73. 
Krek, A., Grun, D., Poy, M.N., Wolf, R., Rosenberg, L., Epstein, E.J., MacMenamin, P., da Piedade, I., Gunsalus, K.C., Stoffel, M., et al. (2005). Combinatorial microRNA target predictions. Nature Genetics 37, 495-500.

Krutzfeldt, J., Rajewsky, N., Braich, R., Rajeev, K.G., Tuschl, T., Manoharan, M., and Stoffel, M. (2005). Silencing of microRNAs in vivo with 'antagomirs'. Nature 438, 685-689.

Kumar, D. (2015). Synthetic Gene Complementation to Determine Off-Target Silencing. In Plant Gene Silencing: Methods and Protocols, pp. 281-293.

Kumar, D., Singh, D., Kanodia, P., Prabhu, K.V., Kumar, M., and Mukhopadhyay, K. (2014). Discovery of novel leaf rust responsive microRNAs in wheat and prediction of their target genes. Journal of Nucleic Acids 2014, 570176-570176.

Kurubanjerdjit, N., Huang, C.H., Lee, Y.L., Tsai, J.J.P., and Ng, K.L. (2013). Prediction of microRNA-regulated protein interaction pathways in Arabidopsis using machine learning algorithms. Computers in Biology and Medicine 43, 1645-1652.

Lagana, A. (2015). Computational Prediction of microRNA Targets. In Microrna: Basic Science: From Molecular Biology to Clinical Practice, pp. 231-252.

Lagos-Quintana, M., Rauhut, R., Lendeckel, W., and Tuschl, T. (2001). Identification of novel genes coding for small expressed RNAs. Science 294, 853-858.

Lau, N.C., Lim, L.P., Weinstein, E.G., and Bartel, D.P. (2001). An abundant class of tiny RNAs with probable regulatory roles in Caenorhabditis elegans. Science 294, 858-862.

Law, P.T., Qin, H., Chan, T.F., and Wong, N. (2013). Experimental verification of microRNA targets is essential, prediction alone is insufficient. Carcinogenesis 34, 723-723.

Lee, R.C., and Ambros, V. (2001). An extensive class of small RNAs in Caenorhabditis elegans. Science 294, 862-864.

Leoni, G., and Tramontano, A. (2016). A structural view of microRNA-target recognition. Nucleic acids research.

Leung, A.K.L., Young, A.G., Bhutkar, A., Zheng, G.X., Bosson, A.D., Nielsen, C.B., and Sharp, P.A. (2011). Genome-wide identification of Ago2 binding sites from mouse embryonic stem cells with and without mature microRNAs. Nature Structural \& Molecular Biology 18, 237-U309.

Lewis, B.P., Burge, C.B., and Bartel, D.P. (2005). Conserved seed pairing, often flanked by adenosines, indicates that thousands of human genes are microRNA targets. Cell 120, 15-20.

Lewis, B.P., Shih, I.H., Jones-Rhoades, M.W., Bartel, D.P., and Burge, C.B. (2003). Prediction of mammalian microRNA targets. Cell 115, 787-798.

Li, C., Liu, Z., Yang, F., Liu, W., Wang, D., Dong, E., Wang, Y., Wu, C.I., and Lu, X. (2015). siRNAs with decreased off-target effect facilitate the identification of essential genes in cancer cells, pp. 21603-21613.

Li, J.J., Kim, T.H., Nutiu, R., Ray, D., Hughes, T.R., and Zhang, Z.L. (2014). Identifying mRNA sequence elements for target recognition by human Argonaute proteins. Genome Research 24, 775-785.

Li, Y., and Zhang, C.Y. (2012). Analysis of MicroRNA-Induced Silencing Complex-Involved MicroRNA-Target Recognition by Single-Molecule Fluorescence Resonance Energy Transfer. Analytical Chemistry 84, 5097-5102.

Li, Y., and Zhang, Z.L. (2015). Computational Biology in microRNA. Wiley Interdisciplinary Reviews-Rna 6, 435-452. 
Li, Y.F., and Sunkar, R. (2013). Global identification of small RNA targets in plants by sequencing sliced ends of messenger RNAs, pp. 119-129.

Lim, L.P., Lau, N.C., Garrett-Engele, P., Grimson, A., Schelter, J.M., Castle, J., Bartel, D.P., Linsley, P.S., and Johnson, J.M. (2005). Microarray analysis shows that some microRNAs downregulate large numbers of target mRNAs. Nature 433, 769-773.

Lin, X., Morgan-Lappe, S., Huang, X., Li, L., Zakula, D.M., Vernetti, L.A., Fesik, S.W., and Shen, Y. (2007). 'Seed' analysis of off-target siRNAs reveals an essential role of Mcl-1 in resistance to the small-molecule Bcl-2/Bcl-X-L inhibitor ABT-737. Oncogene 26, 3972-3979.

Lin, X.Y., Ruan, X., Anderson, M.G., McDowell, J.A., Kroeger, P.E., Fesik, S.W., and Shen, Y. (2005). siRNA-mediated off-target gene silencing triggered by a $7 \mathrm{nt}$ complementation. Nucleic Acids Research 33, 4527-4535.

Liu, C.C., Mallick, B., Long, D., Rennie, W.A., Wolenc, A., Carmack, C.S., and Ding, Y. (2013). CLIP-based prediction of mammalian microRNA binding sites. Nucleic Acids Research 41, e138-e138.

Liu, C.C., Rennie, W.A., Mallick, B., Kanoria, S., Long, D., Wolenc, A., Carmack, C.S., and Ding, Y. (2014a). MicroRNA binding sites in C. elegans 3 ' UTRs. Rna Biology 11, 693-701.

Liu, J., Carmell, M.A., Rivas, F.V., Marsden, C.G., Thomson, J.M., Song, J.J., Hammond, S.M., Joshua-Tor, L., and Hannon, G.J. (2004). Argonaute2 is the catalytic engine of mammalian RNAi. Science 305, 1437-1441.

Liu, Q.K., Wang, F., and Axtell, M.J. (2014b). Analysis of Complementarity Requirements for Plant MicroRNA Targeting Using a Nicotiana benthamiana Quantitative Transient Assay. Plant Cell 26, 741-753.

Llave, C., Xie, Z., Kasschau, K.D., and Carrington, J.C. (2002). Cleavage of Scarecrow-like mRNA targets directed by a class of Arabidopsis miRNA. Science 297, 2053-2056.

Long, D., Lee, R., Williams, P., Chan, C.Y., Ambros, V., and Ding, Y. (2007). Potent effect of target structure on microRNA function. Nature Structural \& Molecular Biology 14, 287-294.

Lu, S., and Cullen, B.R. (2004). Adenovirus VA1 noncoding RNA can inhibit small interfering RNA and MicroRNA biogenesis. J Virol 78, 12868-12876.

Lytle, J.R., Yario, T.A., and Steitz, J.A. (2007). Target mRNAs are repressed as efficiently by microRNA-binding sites in the 5 ' UTR as in the 3 ' UTR. America 104, 9667-9672.

Ma, J.B., Yuan, Y.R., Meister, G., Pei, Y., Tuschl, T., and Patel, D.J. (2005). Structural basis for 5 '-end-specific recognition of guide RNA by the A-fulgidus Piwi protein. Nature 434, 666-670.

Ma, Y., Creanga, A., Lum, L., and Beachy, P.A. (2006). Prevalence of off-target effects in Drosophila RNA interference screens. Nature 443, 359-363.

Majoros, W.H., Lekprasert, P., Mukherjee, N., Skalsky, R.L., Corcoran, D.L., Cullen, B.R., and Ohler, U. (2013). MicroRNA target site identification by integrating sequence and binding information. Nat Methods 10, 630-633.

Majoros, W.H., and Ohler, U. (2007). Spatial preferences of microRNA targets in 3 ' untranslated regions. Bmc Genomics 8, 152-152.

Maragkakis, M., Reczko, M., Simossis, V.A., Alexiou, P., Papadopoulos, G.L., Dalamagas, T., Giannopoulos, G., Goumas, G., Koukis, E., Kourtis, K., et al. (2009). DIANA-microT web server: elucidating microRNA functions through target prediction. Nucleic Acids Research 37, W273-W276. 
Maragkakis, M., Vergoulis, T., Alexiou, P., Reczko, M., Plomaritou, K., Gousis, M., Kourtis, K., Koziris, N., Dalamagas, T., and Hatzigeorgiou, A.G. (2011). DIANA-microT Web server upgrade supports Fly and Worm miRNA target prediction and bibliographic miRNA to disease association. Nucleic Acids Research 39, W145-W148.

Marin, R.M., Voellmy, F., von Erlach, T., and Vanicek, J. (2012). Analysis of the accessibility of CLIP bound sites reveals that nucleation of the miRNA:mRNA pairing occurs preferentially at the 3 '-end of the seed match. Rna-a Publication of the Rna Society 18, 1760-1770.

Martin, H.C., Wani, S., Steptoe, A.L., Krishnan, K., Nones, K., Nourbakhsh, E., Vlassov, A., Grimmond, S.M., and Cloonan, N. (2014). Imperfect centered miRNA binding sites are common and can mediate repression of target mRNAs. Genome Biology 15, R51-R51.

Martin, S.E., and Caplen, N.J. (2006). Mismatched siRNAs downregulate mRNAs as a function of target site location. Febs Letters 580, 3694-3698.

Megraw, M., Sethupathy, P., Corda, B., and Hatzigeorgiou, A.G. (2007). miRGen: a database for the study of animal microRNA genomic organization and function. Nucleic Acids Research 35, D149-D155.

Meister, G., Landthaler, M., Patkaniowska, A., Dorsett, Y., Teng, G., and Tuschl, T. (2004). Human Argonaute2 mediates RNA cleavage targeted by miRNAs and siRNAs. Mol Cell 15, 185-197.

Mishra, A.K., Duraisamy, G.S., and Matousek, J. (2015). Discovering MicroRNAs and Their Targets in Plants. Critical Reviews in Plant Sciences 34, 553-571.

Mohr, S.E., Smith, J.A., Shamu, C.E., Neumuller, R.A., and Perrimon, N. (2014). RNAi screening comes of age: improved techniques and complementary approaches. Nature Reviews Molecular Cell Biology 15, 591-600.

Moore, M.J., Scheel, T.K.H., Luna, J.M., Park, C.Y., Fak, J.J., Nishiuchi, E., Rice, C.M., and Darnell, R.B. (2015). miRNA-target chimeras reveal miRNA 3 '-end pairing as a major determinant of Argonaute target specificity. Nature Communications 6, 8864-8864.

Muckstein, U., Tafer, H., Hackermuller, J., Bernhart, S.H., Stadler, P.F., and Hofacker, I.L. (2006). Thermodynamics of RNA-RNA binding. Bioinformatics 22, 1177-1182.

Mullany, L.E., Herrick, J.S., Wolff, R.K., and Slattery, M.L. (2016). MicroRNA Seed Region Length Impact on Target Messenger RNA Expression and Survival in Colorectal Cancer. PloS one 11, e0154177-e0154177.

Naito, Y., and Ui-Tei, K. (2013). Designing functional siRNA with reduced off-target effects. Methods in Molecular Biology 942, 57-68.

Naito, Y., Yoshimura, J., Morishita, S., and Ui-Tei, K. (2009). siDirect 2.0: updated software for designing functional siRNA with reduced seed-dependent off-target effect. Bmc Bioinformatics 10, 392-392.

Nakanishi, K., Ascano, M., Gogakos, T., Ishibe-Murakami, S., Serganov, A.A., Briskin, D., Morozov, P., Tuschl, T., and Patel, D.J. (2013). Eukaryote-Specific Insertion Elements Control Human ARGONAUTE Slicer Activity. Cell Reports 3, 1893-1900.

Nam, J.W., Rissland, O.S., Koppstein, D., Abreu-Goodger, C., Jan, C.H., Agarwal, V., Yildirim, M.A., Rodriguez, A., and Bartel, D.P. (2014a). Global Analyses of the Effect of Different Cellular Contexts on MicroRNA Targeting. Molecular Cell 53, 1031-1043.

Nam, S., Ryu, H., Son, W.J., Kim, Y.H., Kim, K.T., Balch, C., Nephew, K.P., and Lee, J. (2014b). $\mathrm{Mg} 2+$ Effect on Argonaute and RNA Duplex by Molecular Dynamics and Bioinformatics Implications. Plos One 9, e109745-e109745. 
Nielsen, C.B., Shomron, N., Sandberg, R., Hornstein, E., Kitzman, J., and Burge, C.B. (2007). Determinants of targeting by endogenous and exogenous microRNAs and siRNAs. Rna-a Publication of the Rna Society 13, 1894-1910.

Nolte, A., Ott, K., Rohayem, J., Walker, T., Schlensak, C., and Wendel, H.P. (2013). Modification of small interfering RNAs to prevent off-target effects by the sense strand. New Biotechnology 30 , 159-165.

Orom, U.A., and Lund, A.H. (2007). Isolation of microRNA targets using biotinylated synthetic microRNAs. Methods 43, 162-165.

Paraskevopoulou, M.D., Georgakilas, G., Kostoulas, N., Reczko, M., Maragkakis, M., Dalamagas, T.M., and Hatzigeorgiou, A.G. (2013a). DIANA-LncBase: experimentally verified and computationally predicted microRNA targets on long non-coding RNAs. Nucleic Acids Research 41, D239-D245.

Paraskevopoulou, M.D., Georgakilas, G., Kostoulas, N., Vlachos, I.S., Vergoulis, T., Reczko, M., Filippidis, C., Dalamagas, T., and Hatzigeorgiou, A.G. (2013b). DIANA-microT web server v5.0: service integration into miRNA functional analysis workflows. Nucleic Acids Research 41, W169-W173.

Paraskevopoulou, M.D., Vlachos, I.S., Karagkouni, D., Georgakilas, G., Kanellos, I., Vergoulis, T., Zagganas, K., Tsanakas, P., Floros, E., Dalamagas, T., et al. (2016). DIANA-LncBase v2: indexing microRNA targets on non-coding transcripts. Nucleic Acids Research 44, D231-D238.

Park, J.H., Ahn, S., Kim, S., Lee, J., Nam, J.W., and Shin, C. (2013). Degradome sequencing reveals an endogenous microRNA target in C. elegans. Febs Letters 587, 964-969.

Parker, J.S., Roe, S.M., and Barford, D. (2004). Crystal structure of a PIWI protein suggests mechanisms for siRNA recognition and slicer activity. Embo Journal 23, 4727-4737.

Parker, J.S., Roe, S.M., and Barford, D. (2005). Structural insights into mRNA recognition from a PIWI domain-siRNA guide complex. Nature 434, 663-666.

Pasquinelli, A.E. (2012). MicroRNAs and their targets: recognition, regulation and an emerging reciprocal relationship. Nat Rev Genet 13, 271-282.

Peacock, H., Kannan, A., Beal, P.A., and Burrows, C.J. (2011). Chemical Modification of siRNA Bases To Probe and Enhance RNA Interference. Journal of Organic Chemistry 76, 7295-7300.

Peterson, S.M., Thompson, J.A., Ufkin, M.L., Sathyanarayana, P., Liaw, L., and Congdon, C.B. (2014). Common features of microRNA target prediction tools. Frontiers in genetics 5, 23-23.

Petri, S., Dueck, A., Lehmann, G., Putz, N., Rudel, S., Kremmer, E., and Meister, G. (2011). Increased siRNA duplex stability correlates with reduced off-target and elevated on-target effects. Rna 17 , 737-749.

Petri, S., and Meister, G. (2013). siRNA design principles and off-target effects. Methods in molecular biology (Clifton, NJ) 986, 59-71.

Qiu, S.B., Lane, T.R., and Yang, C.D. (2007). Efficient search algorithms for RNAi target detection. Journal of Supercomputing 42, 303-319.

Reczko, M., Maragkakis, M., Alexiou, P., Papadopoulos, G.L., and Hatzigeorgiou, A.G. (2011). Accurate microRNA Target Prediction Using Detailed Binding Site Accessibility and Machine Learning on Proteomics Data. Frontiers in genetics 2, 103-103.

Rennie, W., Liu, C.C., Carmack, C.S., Wolenc, A., Kanoria, S., Lu, J., Long, D., and Ding, Y. (2014). STarMir: a web server for prediction of microRNA binding sites. Nucleic Acids Research 42, W114-W118. 
Rhoades, M.W., Reinhart, B.J., Lim, L.P., Burge, C.B., Bartel, B., and Bartel, D.P. (2002). Prediction of plant microRNA targets. Cell 110, 513-520.

Ristevski, B. (2015). Overview of Computational Approaches for Inference of MicroRNA-Mediated and Gene Regulatory Networks. In Advances in Computers, Vol 97, pp. 111-145.

Salomon, W.E., Jolly, S.M., Moore, M.J., Zamore, P.D., and Serebrov, V. (2015). Single-Molecule Imaging Reveals that Argonaute Reshapes the Binding Properties of Its Nucleic Acid Guides. Cell 162, 84-95.

Saxena, S., Jonsson, Z.O., and Dutta, A. (2003). Small RNAs with imperfect match to endogenous mRNA repress translation - Implications for off-target activity of small inhibitory RNA in mammalian cells. Journal of Biological Chemistry 278, 44312-44319.

Scacheri, P.C., Rozenblatt-Rosen, O., Caplen, N.J., Wolfsberg, T.G., Umayam, L., Lee, J.C., Hughes, C.M., Shanmugam, K.S., Bhattacharjee, A., Meyerson, M., et al. (2004). Short interfering RNAs can induce unexpected and divergent changes in the levels of untargeted proteins in mammalian cells. America 101, 1892-1897.

Schirle, N.T., Kinberger, G.A., Murray, H.F., Lima, W.F., Prakash, T.P., and MacRae, I.J. (2016). Structural Analysis of Human Argonaute-2 Bound to a Modified siRNA Guide. J Am Chem Soc 138, 8694-8697.

Schirle, N.T., and MacRae, I.J. (2012). The Crystal Structure of Human Argonaute2. Science 336, 1037-1040.

Schirle, N.T., Sheu-Gruttadauria, J., Chandradoss, S.D., Joo, C., and MacRae, I.J. (2015). Water-mediated recognition of t1-adenosine anchors Argonaute2 to microRNA targets. Elife 4.

Schirle, N.T., Sheu-Gruttadauria, J., and MacRae, I.J. (2014). Structural basis for microRNA targeting. Science 346, 608-613.

Schubert, S., Grunweller, A., Erdmann, V.A., and Kurreck, J. (2005). Local RNA target structure influences siRNA efficacy: systematic analysis of intentionally designed binding regions. Journal of Molecular Biology 348, 883-893.

Schwarz, D.S., Ding, H.L., Kennington, L., Moore, J.T., Schelter, J., Burchard, J., Linsley, P.S., Aronin, N., Xu, Z.S., and Zamore, P.D. (2006). Designing siRNA that distinguish between genes that differ by a single nucleotide. Plos Genetics 2, 1307-1318.

Seok, H., Ham, J., Jang, E.S., and Chi, S.W. (2016a). MicroRNA Target Recognition: Insights from Transcriptome-Wide Non-Canonical Interactions. Molecules and cells.

Seok, H., Jang, E.-S., and Chi, S.W. (2016b). Rationally designed siRNAs without miRNA-like off-target repression. Bmb Reports 49, 135-136.

Sethupathy, P., Corda, B., and Hatzigeorgiou, A.G. (2006). TarBase: A comprehensive database of experimentally supported animal microRNA targets. Rna-a Publication of the Rna Society 12, 192-197.

Shao, C.G., Chen, M., and Meng, Y.J. (2013). A reversed framework for the identification of microRNA-target pairs in plants. Briefings in Bioinformatics 14, 293-301.

Shao, Y., Chan, C.Y., Maliyekkel, A., Lawrence, C.E., Roninson, I.B., and Ding, Y. (2007). Effect of target secondary structure on RNAi efficiency. Rna-a Publication of the Rna Society 13, $1631-1640$.

Shweta, and Khan, J.A. (2014). In silico prediction of cotton (Gossypium hirsutum) encoded microRNAs targets in the genome of Cotton leaf curl Allahabad virus. Bioinformation 10, 251-255. 
Singh, N., Srivastava, S., and Sharma, A. (2016). Identification and analysis of miRNAs and their targets in ginger using bioinformatics approach. Gene 575, 570-576.

Singh, S., Wu, X.Y., Ljosa, V., Bray, M.A., Piccioni, F., Root, D.E., Doench, J.G., Boehm, J.S., and Carpenter, A.E. (2015). Morphological Profiles of RNAi-Induced Gene Knockdown Are Highly Reproducible but Dominated by Seed Effects. Plos One 10, e0131370-e0131370.

Snead, N.M., Escamilla-Powers, J.R., Rossi, J.J., and McCaffrey, A.P. (2013). 5 ‘ Unlocked Nucleic Acid Modification Improves siRNA Targeting. Molecular Therapy-Nucleic Acids 2, e103-e103.

Snove, O., and Holen, T. (2004). Many commonly used siRNAs risk off-target activity. Biochemical and Biophysical Research Communications 319, 256-263.

Snove, O., and Rossi, J.J. (2006). Chemical modifications rescue off-target effects of RNAi. Acs Chemical Biology 1, 274-276.

Song, J.J., Smith, S.K., Hannon, G.J., and Joshua-Tor, L. (2004). Crystal structure of Argonaute and its implications for RISC slicer activity. Science 305, 1434-1437.

Sood, P., Krek, A., Zavolan, M., Macino, G., and Rajewsky, N. (2006). Cell-type-specific signatures of microRNAs on target mRNA expression. America 103, 2746-2751.

Srivastava, P.K., Moturu, T.R., Pandey, P., Baldwin, I.T., and Pandey, S.P. (2014). A comparison of performance of plant miRNA target prediction tools and the characterization of features for genome-wide target prediction. Bmc Genomics 15, 348-348.

Stalder, L., Heusermann, W., Sokol, L., Trojer, D., Wirz, J., Hean, J., Fritzsche, A., Aeschimann, F., Pfanzagl, V., Basselet, P., et al. (2013). The rough endoplasmatic reticulum is a central nucleation site of siRNA-mediated RNA silencing. EMBO J 32, 1115-1127.

Stark, A., Brennecke, J., Russell, R.B., and Cohen, S.M. (2003). Identification of Drosophila MicroRNA targets. Plos Biology 1, 397-409.

Su, X.P., Wang, H.M., Ge, W., Yang, M.J., Hou, J., Chen, T.Y., Li, N., and Cao, X.T. (2015). An In Vivo Method to Identify microRNA Targets Not Predicted by Computation Algorithms: p21 Targeting by miR-92a in Cancer. Cancer Research 75, 2875-2885.

Svoboda, P. (2007). Off-targeting and other non-specific effects of RNAi experiments in mammalian cells. Curr Opin Mol Ther 9, 248-257.

Svoboda, P. (2014). Renaissance of mammalian endogenous RNAi. FEBS Lett 588, 2550-2556.

Svoboda, P. (2015). A toolbox for miRNA analysis. FEBS Lett 589, 1694-1701.

Tafer, H. (2014). Bioinformatics of sirna design. Methods in Molecular Biology 1097, 477-490.

Tafer, H., Ameres, S.L., Obernosterer, G., Gebeshuber, C.A., Schroeder, R., Martinez, J., and Hofacker, I.L. (2008). The impact of target site accessibility on the design of effective siRNAs. Nature Biotechnology 26, 578-583.

Tan, S.M., and Lieberman, J. (2016). Capture and Identification of miRNA Targets by Biotin Pulldown and RNA-seq. In Post-Transcriptional Gene Regulation, 2nd Edition, pp. 211-228.

Tarang, S., and Weston, M.D. (2014). Macros in microRNA target identification A comparative analysis of in silico, in vitro, and in vivo approaches to microRNA target identification. Rna Biology 11, 324-333.

Thomson, D.W., Bracken, C.P., and Goodall, G.J. (2011). Experimental strategies for microRNA target identification. Nucleic Acids Research 39, 6845-6853.

Vatolin, S., Navaratne, K., and Weil, R.J. (2006). A novel method to detect functional microRNA targets. Journal of Molecular Biology 358, 983-996. 
Vencken, S., Hassan, T., McElvaney, N.G., Smith, S.G.J., and Greene, C.M. (2015). miR-CATCH: MicroRNA Capture Affinity Technology. In Rna Interference: Challenges and Therapeutic Opportunities, pp. 365-373.

Vergoulis, T., Vlachos, I.S., Alexiou, P., Georgakilas, G., Maragkakis, M., Reczko, M., Gerangelos, S., Koziris, N., Dalamagas, T., and Hatzigeorgiou, A.G. (2012). TarBase 6.0: capturing the exponential growth of miRNA targets with experimental support. Nucleic Acids Research 40, D222-D229.

Vlachos, I.S., Kostoulas, N., Vergoulis, T., Georgakilas, G., Reczko, M., Maragkakis, M., Paraskevopoulou, M.D., Prionidis, K., Dalamagas, T., and Hatzigeorgiou, A.G. (2012). DIANA miRPath v.2.0: investigating the combinatorial effect of microRNAs in pathways. Nucleic Acids Research 40, W498-W504.

Vosa, U., Esko, T., Kasela, S., and Annilo, T. (2015). Altered Gene Expression Associated with microRNA Binding Site Polymorphisms. Plos One 10, e0141351-e0141351.

Wang, F., Polydore, S., and Axtell, M.J. (2015). More than meets the eye? Factors that affect target selection by plant miRNAs and heterochromatic siRNAs. Current Opinion in Plant Biology 27, 118-124.

Wang, P., Ning, S.W., Wang, Q.H., Li, R.H., Ye, J.R., Zhao, Z.X.L., Li, Y., Huang, T., and Li, X. (2013). mirTarPri: Improved Prioritization of MicroRNA Targets through Incorporation of Functional Genomics Data. Plos One 8, e53685-e53685.

Wang, T., Chen, B.B., Kim, M.S., Xie, Y., and Xiao, G.H. (2014). A Model-Based Approach to Identify Binding Sites in CLIP-Seq Data. Plos One 9, e93248-e93248.

Wang, X.W. (2014). Composition of seed sequence is a major determinant of microRNA targeting patterns. Bioinformatics 30, 1377-1383.

Wang, Y., Li, L., Tang, S., Liu, J., Zhang, H., Zhi, H., Jia, G., and Diao, X. (2016). Combined small RNA and degradome sequencing to identify miRNAs and their targets in response to drought in foxtail millet. BMC Genetics 17, 57-57.

Wang, Y.L., Juranek, S., Li, H.T., Sheng, G., Tuschl, T., and Patel, D.J. (2008). Structure of an argonaute silencing complex with a seed-containing guide DNA and target RNA duplex. Nature 456, 921-U972.

Wang, Y.L., Juranek, S., Li, H.T., Sheng, G., Wardle, G.S., Tuschl, T., and Patel, D.J. (2009). Nucleation, propagation and cleavage of target RNAs in Ago silencing complexes. Nature 461, 754-U753.

Wee, L.M., Flores-Jasso, C.F., Salomon, W.E., and Zamore, P.D. (2012). Argonaute Divides Its RNA Guide into Domains with Distinct Functions and RNA-Binding Properties. Cell 151, 1055-1067.

Wei, K., Yan, F., Xiao, H., Yang, X.X., Xie, G.E., Xiao, Y., Wang, T.T., Xun, Y., Huang, Z.Q., Han, M., et al. (2014). Affinity Purification of Binding miRNAs for Messenger RNA Fused with a Common Tag. International Journal of Molecular Sciences 15, 14753-14765.

Xie, P., Liu, Y., Li, Y.D., Zhang, M.Q., and Wang, X.W. (2014). MIROR: a method for cell-type specific microRNA occupancy rate prediction. Molecular Biosystems 10, 1377-1384.

Xing, L.B., Zhang, D., Li, Y.M., Zhao, C.P., Zhang, S.W., Shen, Y.W., An, N., and Han, M.Y. (2014). Genome-wide identification of vegetative phase transition-associated microRNAs and target predictions using degradome sequencing in Malus hupehensis. Bmc Genomics 15, 1125-1125.

Xu, P., Zhang, Y.J., Kang, L., Roossinck, M.J., and Mysore, K.S. (2006). Computational estimation and experimental verification of off-target silencing during posttranscriptional gene silencing in plants. Plant Physiology 142, 429-440. 
Xu, W.L., San Lucas, A., Wang, Z.X., and Liu, Y. (2014a). Identifying microRNA targets in different gene regions. Bmc Bioinformatics 15, S4-S4.

Xu, W.L., Wang, Z.X., and Liu, Y. (2014b). The Characterization of microRNA-Mediated Gene Regulation as Impacted by Both Target Site Location and Seed Match Type. Plos One 9, e108260-e108260.

Yamada, T., and Morishita, S. (2005). Accelerated off-target search algorithm for siRNA. Bioinformatics 21, 1316-1324.

Yang, J.H., Li, J.H., Shao, P., Zhou, H., Chen, Y.Q., and Qu, L.H. (2011). starBase: a database for exploring microRNA-mRNA interaction maps from Argonaute CLIP-Seq and Degradome-Seq data. Nucleic Acids Research 39, D202-D209.

Yao, C.Y., Sasaki, H.M., Ueda, T., Tomari, Y., and Tadakuma, H. (2015). Single-Molecule Analysis of the Target Cleavage Reaction by the Drosophila RNAi Enzyme Complex. Molecular Cell 59, 125-132.

Yekta, S., Shih, I.H., and Bartel, D.P. (2004). MicroRNA-directed cleavage of HOXB8 mRNA. Science 304, 594-596.

Yi, R., Doehle, B.P., Qin, Y., Macara, I.G., and Cullen, B.R. (2005). Overexpression of exportin 5 enhances RNA interference mediated by short hairpin RNAs and microRNAs. Rna 11, 220-226.

Yilmazel, B., Hu, Y.H., Sigoillot, F., Smith, J.A., Shamu, C.E., Perrimon, N., and Mohr, S.E. (2014). Online GESS: prediction of miRNA-like off-target effects in large-scale RNAi screen data by seed region analysis. Bmc Bioinformatics 15, 192-192.

Yuan, Y.R., Pei, Y., Ma, J.B., Kuryavyi, V., Zhadina, M., Meister, G., Chen, H.Y., Dauter, Z., Tuschl, T., and Patel, D.J. (2005). Crystal structure of A. aeolicus argonaute, a site-specific DNA-guided endoribonuclease, provides insights into RISC-mediated mRNA cleavage. Mol Cell 19, 405-419.

Zander, A., Holzmeister, P., Klose, D., Tinnefeld, P., and Grohmann, D. (2014). Single-molecule FRET supports the two-state model of argonaute action. RNA Biology 11, 45-56.

Zeng, Y., Yi, R., and Cullen, B.R. (2003). MicroRNAs and small interfering RNAs can inhibit mRNA expression by similar mechanisms. America 100, 9779-9784.

Zhong, R., Kim, J., Kim, H.S., Kim, M., Lum, L., Levine, B., Xiao, G.H., White, M.A., and Xie, Y. (2014). Computational detection and suppression of sequence-specific off-target phenotypes from whole genome RNAi screens. Nucleic Acids Research 42, 8214-8222.

Zisoulis, D.G., Lovci, M.T., Wilbert, M.L., Hutt, K.R., Liang, T.Y., Pasquinelli, A.E., and Yeo, G.W. (2010). Comprehensive discovery of endogenous Argonaute binding sites in Caenorhabditis elegans. Nature Structural \& Molecular Biology 17, 173-U176. 